\title{
Characterization and evolution of the sediments of a Mediterranean coastal lagoon located next to a former mining area
}

\author{
Gregorio García ${ }^{\mathrm{a}, *}$, Ana Muñoz-Vera ${ }^{\mathrm{b}}$ \\ a Área de Edafología y Química Agrícola, Dpt. Ciencia y Tecnología Agraria, Technical University of Cartagena (UPCT), Paseo de Alfonso XIII, 48., E-30203 Cartagena, Spain \\ b Departamento de Ciencia y Tecnología Agraria, Área de Edafología, Escuela Técnica Superior de Ingeniería Agronómica, Technical University of Cartagena (UPCT), Paseo Alfonso XIII 50, 30203 \\ Cartagena, Spain
}

\section{A R T I C L E I N F O}

\section{Article history:}

Received 13 May 2015

Received in revised form 26 August 2015

Accepted 27 August 2015

Available online $\mathrm{xxxx}$

\section{Keywords:}

Sediments

Metal mining waste

Sedimentation dynamics

Coastal lagoon

Mar Menor (SE Spain)

\begin{abstract}
A B S T R A C T
Coastal lagoons are ecosystems that are relatively enclosed water bodies under the influence of both the terrestrial and the marine environment, being vulnerable to human impacts. Human activities, such as mining extraction, are significant anthropogenic coastal stressors that can negatively affect ecosystems and communities. In light of the above, the objective of this research is to examine the influence of metal mining activities on the composition of sediments of a Mediterranean coastal lagoon, named Mar Menor. This paper presents a comprehensive characterization for grain size, mineralogy, geochemistry and organic matter of sediments of this coastal lagoon, investigating their variation along space and time. Sedimentation dynamics are ruling clearly the grain size predominant in each area of the Mar Menor coastal lagoon, determining the existence of entrainment, transport and sedimentation areas. For minerals, elements and organic matter, sedimentation dynamics are also determining their distribution.
\end{abstract}

(c) 2015 Elsevier Ltd. All rights reserved.

\section{Introduction}

Coastal lagoons are relatively enclosed water bodies under the influence of both the terrestrial and the marine environment. Furthermore, being close to land, they are vulnerable to human impacts (Hodgkin, 1994; Reizopouluo et al., 1996; Fujita et al., 2014). Therefore, environmental characteristics will be conditioned by their immediate surroundings, which will determine both the mineralogical composition of the sediments, and the quality of its waters and the contamination level of the organisms that live inside.

Environmental conditions in coastal lagoons are very changeable due to their confined nature and to their shallowness. Coastal marine systems are particularly vulnerable to the effects of human activities resulting from mining, industry, tourism and urban development. Despite their importance, these systems are among the most vulnerable water environments in the world and they might even be considered as stressed ecosystems. In fact, they are subject to considerable anthropogenic pressures that usually lead to changes in their environmental health (Courrat et al., 2009).

As for other sedimentary environments, the composition of sediments that accumulate within individual coastal lagoons is primarily a

\footnotetext{
* Corresponding author.

E-mail addresses: gregorio.garcia@upct.es (G. García), amv.tana@gmail.com (A. Muñoz-Vera)
}

reflection of three main factors (Perry and Taylor, 2007): the sediment source, the processes of sediment transport and deposition, and the chemical processes operating within the sediment or water column. Increasingly important in many sedimentary systems are inputs of anthropogenically sourced sediments. These include both sediment grains that come from material that is anthropogenic in origin and sedimentary materials that have been heavily impacted by anthropogenic activity.

Human activities, such as mining extraction, are significant anthropogenic coastal stressors that can negatively affect ecosystems and communities through the alteration or loss of littoral habitats, increased pollutant inputs, loss of allochthonous material and changes in food availability (Peterson et al., 2000; Sanger et al., 2004; Seitz et al., 2006). Concerning this, sediment composition may differ significantly with the distance to neighbouring mining areas. This results in the generation of different sediment mineralogy inside the coastal lagoon according to a distance gradient to mining areas, which can produce a specific pollution of water and sediments, as well as a specific composition of flora and fauna (Bilkovic and Roggero, 2008).

Heavy metals and metalloids can be toxic at high concentrations and can affect aquatic organisms, as well as adversely affect human health (Nor, 1987; Silva et al., 2000). These elements usually have dynamic distribution and behaviour in lagoon sediments and their sources can be natural or anthropogenic (Kouassi et al., 2015). High metal content in fauna and flora in lagoons may impart a very important impact on human health, reproduction and, consequently, our survival (Abdallah and Mohamed, 2015; Kouassi et al., 2015). 
On the other hand, marine and coastal lagoon sediments not only support a variety of living organisms that are important for maintaining ecosystem structures and functions, but are also a reservoir for insoluble contaminants such as metals (Chapman and Wang, 2001; Kouassi et al., 2015; Renzi et al., 2015). The bioavailability of sediment-bound contaminants is determined by sediment constituents, overlying and interstitial water chemistry, and the behaviour of organisms (Loring, 1991), and so should be considered as a dynamic process. For this reason, sediment quality and mineralogy assessment in coastal lagoon areas can be an issue of interest for these ecosystems.

In light of the above, the objective of this research was to examine the influence of mining activities on the composition of sediments in a Mediterranean coastal lagoon, as well as discuss the possible causes and mechanisms of the sediment redistribution. These wastes were deposited on the bottom of the lagoon, to the extent that the lagoon itself came to be regarded as a mining deposit (Simonneau, 1973). These mining wastes were initially deposited in the southern basin of the lagoon, although the marine currents and other factors, such as wind, may have generated a redistribution of these sediments across the lagoon. We hypothesized that marine sediment distributions were not uniform across the lagoon's seabed, and those sediment grain size, mineralogy and geochemistry were expected to change over time and between different areas inside this ecosystem.

\section{Material and methods}

\subsection{Study area}

This study is focused in a coastal lagoon named Mar Menor that is placed on the southeastern Iberian Peninsula, Spain (Fig. 1). This water body is one of the largest coastal lagoons in the Mediterranean Sea.
The Mar Menor is a hypersaline coastal lagoon of $135.5 \mathrm{~km}^{2}$, with a maximum length of $21 \mathrm{~km}$ and an average width of around $14 \mathrm{~km}$, with a mean depth of $4.5 \mathrm{~m}$ and a maximum of $7 \mathrm{~m}$ (MartinezAlvarez et al., 2011). It is separated from the Mediterranean Sea by a long sandy bar called La Manga, which has up to five narrow channels that connect it to the open sea. The lagoon shows a salinity range of 39-45 ppt and the temperature varies from $10{ }^{\circ} \mathrm{C}$ in winter to $32^{\circ} \mathrm{C}$ in summer (Perez-Ruzafa et al., 2005). Its coastline is densely populated, supporting a large tourist population during summer months of about half a million people.

The mining district of Cartagena-La Union is located at the South of the lagoon (Fig. 1), and belongs to the eastern part of the Betic Ranges. Mining activities in the mining district date back to many centuries ago, because remains of exploitations belonging to ancient civilizations, including Iberians, Phoenicians, Carthaginians and Romans, have been found. At that time, they extracted mainly gold, silver, lead, zinc, iron and copper (Oen et al., 1975). The Carthaginians extracted large amounts of metals, besides silver, that contributed to increase their power in the war against Rome. Mining in Cartagena revived in the nineteenth century, with the start of underground mining through smallholding exploitations. The mining district of Cartagena-La Union becomes in the late nineteenth century one of the largest producers of lead (Vilar and Egea Bruno, 1990). In 1957 the open pit mining started with the opening of the Emilia quarry (Vilar et al., 1991), while in 1968 underground mining ended, which made way for "open pit" mining, although some isolated mines followed barely subsisting. This prolonged activity has caused quite a visual impact on the area due to the presence of numerous accumulations of mining waste. Between 1957 and 1987 more than 360 million tons of rocks were mobilized. Mining ceased in 1991 due to economic, environmental and social pressures (García, 2004).

The bed sediment grain size composition of the lagoon is predominantly muddy and sandy, with some areas with natural rocky bottoms

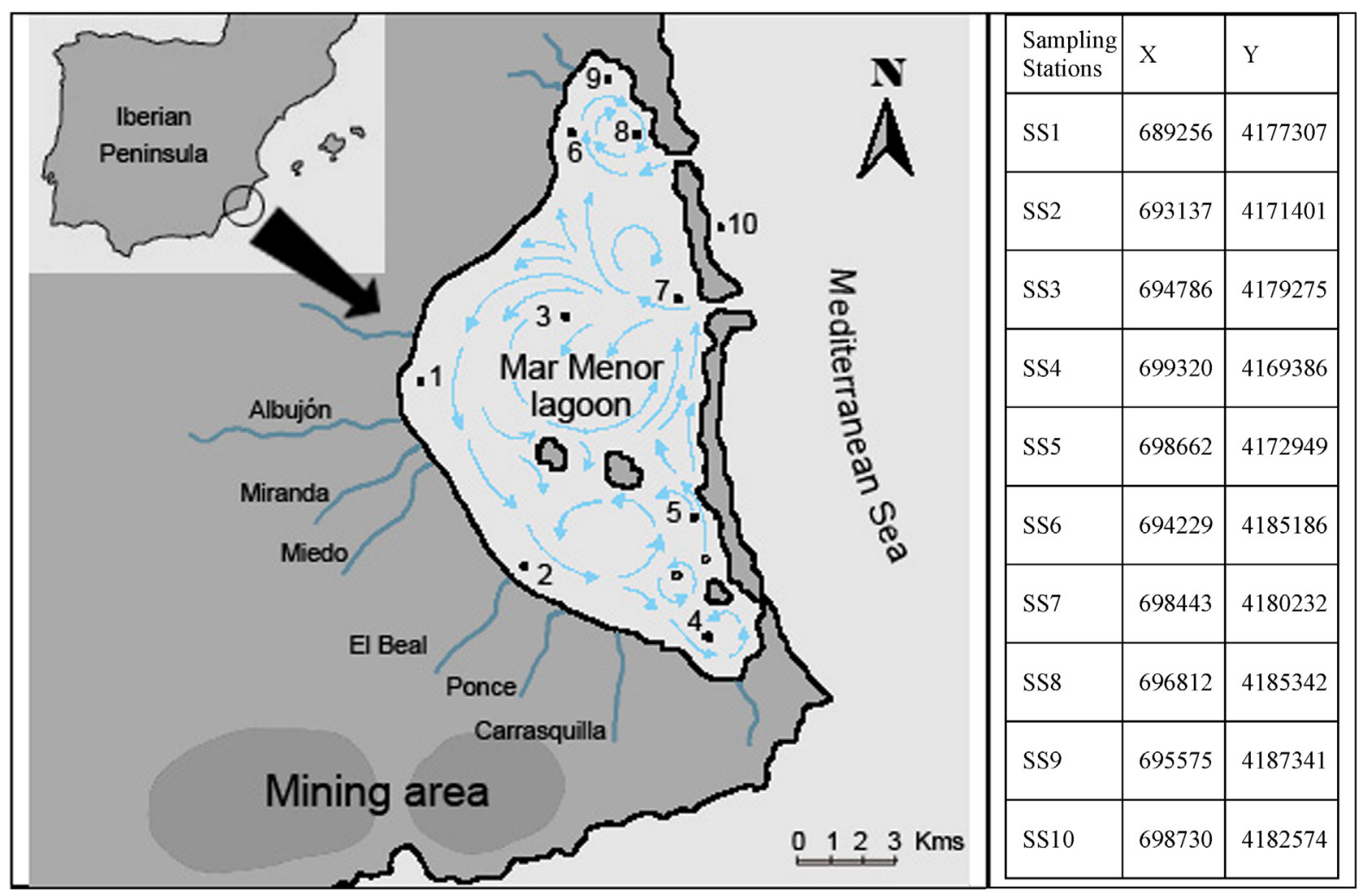

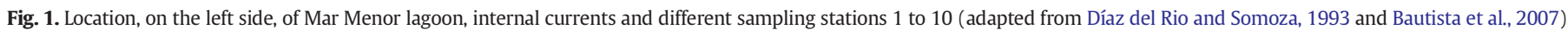
Coordinates, on the right side, presented in UTM ETRS89 for different sampling stations (SS); X = longitude and Y = latitude. 
around islands (Pérez-Ruzafa et al., 2006). Sediments of the Mar Menor present high concentrations of heavy metals due to past mining activities near the lagoon (Simonneau, 1973; De León et al., 1982), to the extent that these sediments have come to be regarded as mining sites (Simonneau, 1973). Although mining activities stopped several decades ago, mining residuals continue to enter the lagoon, especially through seasonal rivers, locally called "ramblas", when torrential rains occur.

\subsection{Sediment sampling}

Surficial sediment samples (10 cm depth) were collected through the manual introduction of polyethylene corers (previously washed in $6 \mathrm{~N} \mathrm{HNO}_{3}$ ) by divers. This depth range allows us to estimate the average value of the parameter considered for the past 30 years over the estimated period consistent with the sedimentation rate estimated for this period by various authors (Pérez-Ruzafa et al., 1987). The depth at the study sites ranges from 1.0 to $5.0 \mathrm{~m}$. Samples were stored in polyethylene containers and transported on ice to the laboratory, where they were stored at $-20^{\circ} \mathrm{C}$, and then dried at $55^{\circ} \mathrm{C}$ until their analysis.

The study was carried out during May 2007 in 10 "Sampling Stations" (SS) (Fig. 1). The sampling stations were selected in such a way to cover all parts of the lagoon: three sampling stations were situated in the south basin of the Mar Menor coastal lagoon (SS2, SS4 and SS5), other three in the middle zone (SS1, SS3 and SS7) and three more in the north part of the lagoon (SS6, SS8 and SS9). SS 10, which was selected as a reference station, is located on the Mediterranean Sea, just close to the limit of the coastal lagoon. SS1 (Albujón) and SS2 (Beal) are located, respectively, at the outlet of the temporary Albujón and Beal ephemeral watercourses (locally called ramblas), in whose flood ways, high concentrations of pesticides and fertilizers coming from agriculture (SS1) and heavy metals coming from mining areas (SS2) still exist (mainly $\mathrm{Pb}, \mathrm{Fe}$ and $\mathrm{Zn}$ ), brought down from the head areas. In the first case, intensive agriculture started in late 70s, and in the second case, the minerals were exploited for centuries because of their rich metalbearing materials (Simonneau, 1973). For all the stations, corers of $10 \mathrm{~cm}$ depth were collected in order to study the current state of these sediments.

On the SS2, SS3 and SS8 (one per part of the lagoon - south, middle and north), corers of $55 \mathrm{~cm}$ depth were taken to estimate the variation of specific parameters with time. For that purpose, frozen cores were cut in sections of $5 \mathrm{~cm}$ wide, except for first section that was separated in two fractions (0-2 and $2-5 \mathrm{~cm})$.

Sediment parameters such as grain size, mineralogy, total metal content and organic matter content were analysed, in order to have enough data to describe sediment origin and pollution. Samples, before being subjected to various analyses, were quartered with the Rotary Micro Riffler, constant speed and average vibration, with the aim of taking a random representation of each sample. The methods have been tested in the laboratory for their accuracy and reproducibility using reference materials and replicates.

\subsubsection{Grain size}

A grain size analysis was done to determinate if there were differences in the size of particles in different parts of the lagoon. The texture of sediments at each point provides us with information about the dominant sediment dynamics in that area. Before grain-size measurements, chemical pre-treatment is essential to isolate discrete particles of the sample and to provide an evenly dispersed suspension of individual particles. Chemical pre-treatment has proven to be a substantial source of measurement error if not properly carried out. In addition, particles may be broken down into smaller grains during the final ultrasonic dispersion (Lu and An, 1997).

The method DIN 38414-S4 was the regulatory test method (compliance test) used to evaluate the performance of the marine sediments. In this test, $1 \mathrm{~g}$ of dry mass of the residue (with a particle size $<2 \mathrm{~mm}$ ) are mixed in $10 \mathrm{ml}$ of water milliQ type I with the $5 \%$ NaHMP solvent, and submitted to an upside down agitation, in a rotary agitator, during $24 \mathrm{~h}$ at room temperature. Some samples were chosen for repeat measurement to confirm the reliability of the grain-size analysis. The results showed that those repeated are generally better than $0.1 \%$.

The grain size was measured using a MASTERSIZER 2000LF (Malvern Instruments Ltd, UK) laser grain-size analyser with a coupled dispersant unit (HIDRO 2000G). This instrument has measurement ranges of $0.02-2000 \mu \mathrm{m}$, and these measurements were grouped in 3 intervals: clay $(0.02-2 \mu \mathrm{m})$, silt $(2-50 \mu \mathrm{m})$ and sand $(50-2000 \mu \mathrm{m})$.

\subsubsection{Mineralogy of sediments}

Some mineral phases, such as greenalite, are characteristics of mining waste. The mineralogy was studied by X-ray diffraction (XRD) for phase identification. This technique provides a rapid and non-destructive method for the analysis of mineral phases present in sediments. Samples for XRD were gently ground by hand with a mortar and pestle. Mineral phases were identified by powder XRD using a Bruker D8 Advance instrument in $\theta-\theta$ mode (Bruker Corporation, Billerica, MA, USA), with CuK $\alpha$ radiation, $40 \mathrm{kV}, 30 \mathrm{~mA}$ and a scintillation detector.

Samples were step-scanned from $5^{\circ}$ to $70^{\circ}$ in $2 \theta$, with 0.05 stepping intervals, $1 \mathrm{~s}$ per step, and a rotation speed of $60 \mathrm{rpm}$. Powder samples were mounted in back-loading plastic holders. Diffraction patterns were evaluated with DIFFRACplus software (specifically with EVA 12.0, a commercial package from Socabim, 2006) and powder diffraction file database PDF2 (ICDD, 2013).

\subsubsection{Geochemistry of sediments}

Some trace elements, such as $\mathrm{S}, \mathrm{Fe}, \mathrm{Zn}$ and $\mathrm{Pb}$, are characteristics of the mining waste present in the Cartagena-La Unión mining district. The geochemistry was studied by wavelength dispersive X-ray fluorescence spectrometry (WDXRF). This methodology provides a rapid and non-destructive method for the analysis of trace and major elements in soil samples. Due to the measurement method and the optical configuration of the spectrometer, elements with atomic number less than 9 could not be measured directly. Instead, thermogravimetric analysis coupled to mass spectrometry (TG-MS) was carried out, mainly to distinguish the carbon dioxide and moisture in the samples. This additional data help to complete a good semi-quantitative analysis.

Samples for WDXRF were grounded in a disc mill for $1 \mathrm{~min}$, to give a final particle size of less than $40 \mu \mathrm{m}$. Sample preparation involved the formation of pressed-powder pellets using $5 \mathrm{~g}$ of sample (Margui et al., 2009). The samples were analysed using a commercial spectrometer Bruker S4 Pioneer (Bruker Corporation, Billerica, MA, USA), equipped with a Rh anticathode X-ray tube $(20-60 \mathrm{kV}, 5-150 \mathrm{~mA}$, and $4 \mathrm{~kW}$ maximum), five analyser crystals (LiF200, LiF220, Ge, PET, and XS-55), a sealed proportional counter for detection of light elements, and a scintillation counter for heavy elements. Both the collimator aperture and the analyser crystal used determined the energy resolution and efficiency for each analytical line. Analyses were performed in vacuum mode to avoid signal losses by air absorption, allowing the detection of low Z elements (González-Fernández et al., 2010). The recorded spectra were evaluated by the fundamental parameters method, using SPECTRAplus software linked to the equipment (specifically EVA 1.7, a commercial package from Bruker-AXS and Socabim (Bruker AXS GmbH, 2006).

To validate the precision and accuracy of the results, standard reference materials (PACS-2; High polluted Marine and Estuarine Sediments, National Research Council, Canada) were checked and parallel replicates were incorporated. The results exhibit good agreement between certified values and data obtained by WDXRF.

\subsubsection{Organic matter}

In comparison with the environmental matrices of air and water, sediments and soils are known to be of a more complex nature; their analytical investigation creates a host of difficulties. Although, methods 
that are more recent can be used for these purposes, thermogravimetry (TG-MS) possess a high potential for characterizing quantitatively and qualitatively soil and sediment organic matter (SOM). The TG-MS technique allows the detection of released organic compounds when heated in a time-resolved manner (Remmler et al., 1995; Alcolea et al., 2010).

An advanced loss of ignition (LOI) study was performed using TGMS. A "TGA/DSC $1 \mathrm{HT}$ " thermogravimetric analyser (Mettler-Toledo $\mathrm{GmbH}$, Schwerzenbach, Switzerland) with a flowing oxygen atmosphere $(50 \mathrm{ml} / \mathrm{min})$ was used for this determination. The temperature was programmed to increase from 30 to $1075{ }^{\circ} \mathrm{C}$ at $30 \mathrm{~K} / \mathrm{min}$, followed by an isothermal segment of $1 \mathrm{~h}$ at this temperature.

All of the TGA measurements were blank-curve corrected and alumina pans of $70-\mu \mathrm{l}$ capacity, without lids, were used. The TGA instrument was coupled to a Balzers Thermostar mass spectrometer (Pfeiffer Vacuum, Asslar, Germany) for gas analysis. Only water vapour and carbon dioxide were analysed. The dwell time for every ion was $10 \mathrm{~s}$ and the cathode voltage in the ion source was 65 V. A "QMS 200M3" model quadrupole mass spectrometer was used (Alcolea et al., 2010).

\section{Results and discussion}

\subsection{Characterization of recent sediments of the Mar Menor}

The Mar Menor is a coastal lagoon with a fairly complex internal dynamic (Fig. 2). Water exchanges are regulated by differences in the sea level between the lagoon, which has no appreciable water level variations, and the open sea, which is subjected to tidal dynamics (Martinez-Alvarez et al., 2011). The average lagoon water renewal time is approximately 0.79 years (Arévalo, 1988) and its circulation is mainly conducted by the pattern of marine currents existing in this lagoon (Díaz del Rio and Somoza, 1993; Bautista et al., 2007), salt and temperature gradients (Martinez-Alvarez et al., 2011), evaporation and wind (Perez-Ruzafa et al., 2005; Polo et al., 2007). In turn, and with local character, flocculation processes can be produced leading to the development of zones of high turbidity and fine sediment deposition (Perry and Taylor, 2007) As a result of this redistribution of sediments, remarkable changes in mineralogy and geochemistry may occur simultaneously.

One of the main sources of sediment supply to this coastal lagoon is the ancient mining district of Cartagena-La Union, located on the southern shore of Mar Menor. This area has been historically a contributor of waste and materials of extraction of metal ores. The spatial redistribution of these mining sediments throughout the coastal lagoon must mainly be the result of the final balance generated by the interaction between factors such as ocean currents, the existence of gradients (temperature and salt) and winds (SIOM, 2014). The texture of the bed of the lagoon may vary depending on the sedimentary character of each area, which determines its character as an entrainment area, as a transport zone or as a deposition point. Knowledge of these sedimentary dynamics may be giving us useful information on the dynamics and redistribution paths of mining waste across the lagoon. Furthermore, the study of mineralogy and geochemistry, in both cases with the use of mineral phases and geochemical element characteristic of mining waste, may be generating relevant information on the degree of dispersion of these residues and the risk associated with them in the accumulation areas.

\subsubsection{Current distribution of particle size}

Grain size is an important parameter both from a descriptive perspective and in order to understand sediment transport and deposition. The transport and deposition of sediment within and through different sedimentary environments may occur within a variety of mediums, and the thresholds for sediment entrainment and transport represent a fundamental control on both, the character and development of specific sedimentary deposits, as well as their response to fluctuating energy regimes. The study of particle size distribution sediment is important for understanding the geohydrological and environmental sedimentation conditions, and enrichment processes for particular components, such as the potentially harmful metals (Pedreros et al., 1996).

Major controls on sediment deposition relate to grain size and flow velocity. Hjulström (1935) demonstrated the relationship that exists between the velocity of fluid flow and the grain size of sediment that can be moved within a fluid. At its most simplistic, this demonstrates that sediment will be deposited when flow rates drop below the fall velocity for a particle of a given size. Nevertheless, the relationship between these two parameters is non-linear so that, for example, much higher flow velocities are required to entrain highly cohesive fine silt and clay-rich sediments. Stokes' law (Perry and Taylor, 2007) determines the rate at which sediment settles within a fluid of a given density. In simple terms, this means that larger sediment grains will settle faster than smaller grains providing they are of equal density. Therefore, it is expected that an increase in seawater speed produces a transportation of finer materials, such as clay and silt, leaving in these areas greater relative abundance of sand (entrainment processes, washed areas). In contrast, there are other areas (deposition processes, deposition areas), in which water velocity is slowed down and thus the proportion of fine materials (clay and silt) increases. Between both areas, there are transport areas (transport processes) characterized by balanced proportions between the fine and coarse materials.

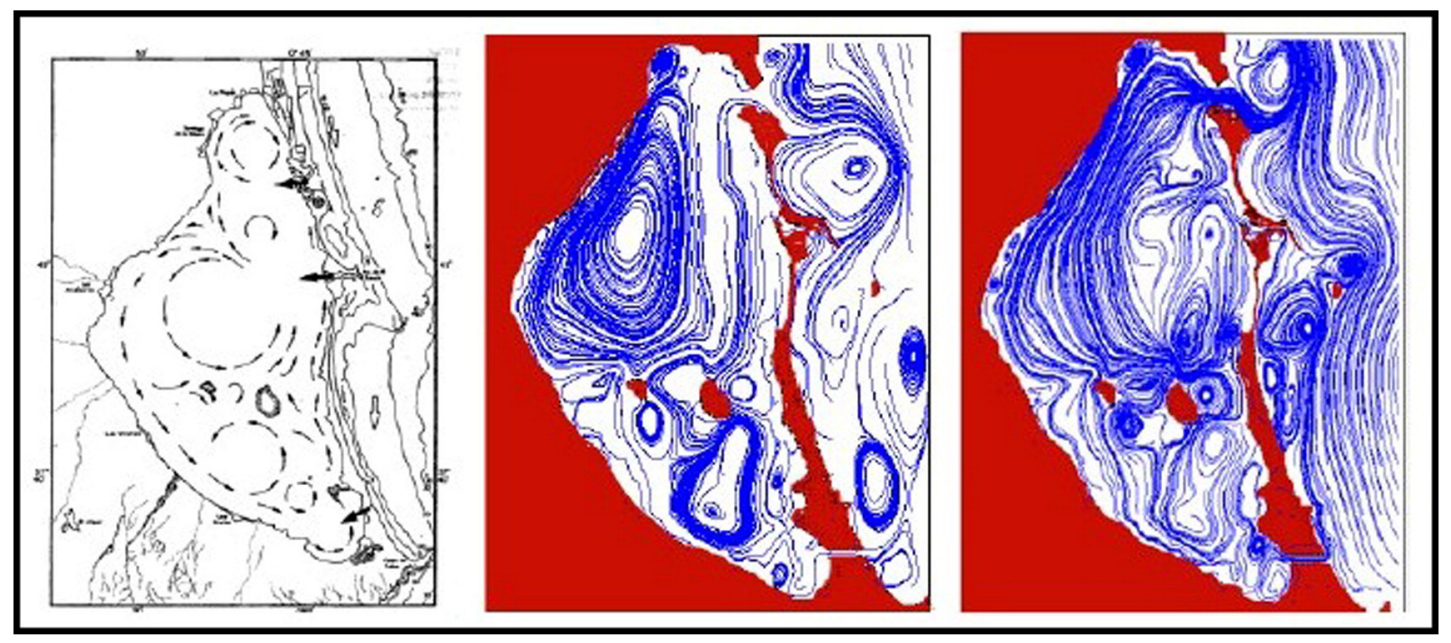

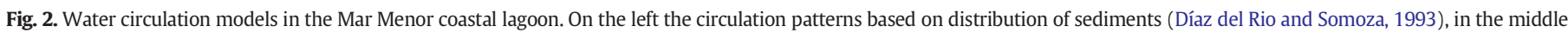
streamlines associated to the velocity field during the emptying phase or low tide, and on the right filling phase or high tide. 
Before beginning this analysis, it should be emphasized that these early results discussed refer to the most recent deposition patterns. In order to study the temporal changes experienced by this parameter, another section of this paper will be focused on a comparison of the evolution of grain size with depth.

In every analysed station, the sediments' dynamics were different (Fig. 3). Therefore, three sampling stations suffered strong drag or entrainment processes (SS1, SS2 and SS10, the last one placed in the Mediterranean Sea). For these cases, the sediment textures were primarily loamy sand. An intermediate case is SS8; although it has a sandy loam texture, it's very close to the loamy sand texture, showing therefore a washing behaviour, rather than acting as a transition or transport zone. For this sampling station, located in proximity to an interconnection channel between the waters of the coastal lagoon and the Mediterranean Sea, entrainment level is much higher than for the rest of the sampling stations with a sandy loam texture.

Three other sampling stations (SS5, SS7 and SS9) showed a sandy loam texture as a consequence of moderate entrainment processes. These sampling stations correspond to the areas of sediment transport that act as transitional zones between washing and sedimentation areas.

On the other hand, sedimentation processes occurred mainly in SS4 and SS6 that showed silt loam texture but particularly in SS3, the texture of which was silty. Some of this data is similar to that obtained recently by other authors (Marín-Guirao et al., 2005), but differ in other cases to the information provided by older studies (Simonneau, 1973).

In order to understand the dynamics of entrainment and deposition of sediments within the Mar Menor, the circulatory pattern of this coastal lagoon should be detailed. The first study on this topic (Díaz del Rio and Somoza, 1993) evaluated the circulation in the lagoon from a morphological study of the distribution of sediments. It was not, however, until 2007 when the hydrodynamic models of water bodies were addressed using mathematical techniques and, therefore, capable of prediction (Bautista et al., 2007). Mediterranean water entering into the Mar Menor is forced by the dynamics of mass exchange between seas, tidal, as well as the dynamics due to evaporation and wind (Polo et al., 2007). At low tide, essentially due to the difference in water levels between the Mar Menor lagoon and the Mediterranean Sea, a net water flow is established from first to second. At this stage, the height of the water column in the Mar Menor exceeds the Mediterranean in up to $1 \mathrm{~m}$ (Bautista et al., 2007). Along the longitudinal direction of

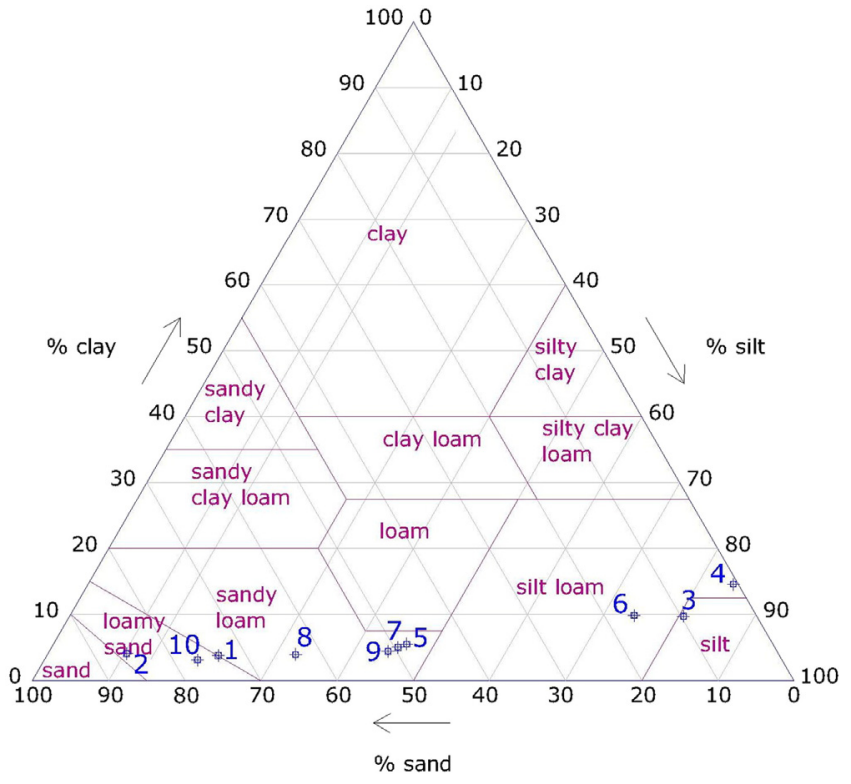

Fig. 3. Sediment texture class of surficial sediments for different sampling stations (each $\mathrm{SS}$ is represented by its number). the Mar Menor, and below the upper layer of the water column, the usual zonal salinity distribution establishes a salt gradient horizontally and therefore pressure-directed from south to north, which should act as an agent force moving the mass of lagoon water to the north, even beyond the front of El Estacio channel. This subsurficial mass advection northward seems to be compensated by another surficial current from the south (the more you advance towards the southern part of the basin the more important it will be), so that there is conservation of mass (volume) through the cross section of the basin. Actually, this surficial component must be due to mass advection from El Estacio channel, extended to the bottom of the basin (Arévalo et al., 2010).

Considering velocity fields it shows that there are two circulation areas separated and well defined: one north and one south of the flow of water from the El Estacio channel (located slightly north of the islands placed in the middle of the lagoon). Although it cannot be confirmed that both areas are physically isolated, the exchange of water between them is less than what would be expected (Bautista et al., 2007). Furthermore, it has been determined that there is a more active water mixture between the two seas in the northern sub-basin in comparison to the southern sub-basin (Mas Hernández, 1996).

In any case, the internal flows of the lagoon are much more complicated than expected, as there are numerous sub-cells, especially located in the southern sub-basin (Bautista et al., 2007). This will establish, in the southern part of the basin, a non-estuarine circulatory system with (more or less mixed) Mediterranean water flowing on the surface to the south, and the water of the lagoon flowing under surface to the north. This cell of haline origin will displace water masses very slowly, according to the magnitude of the horizontal gradient. The closure of the circulatory system of the Mar Menor would be completed through a system of currents that could evacuate its surplus of salt through El Estacio channel. This flow would be directly generated by the dynamics of the mass exchange between seas, exclusively for the periods of water exit, and consist of a boundary stream, attached to the outside of the lagoon coastline, running southbound toward El Estacio channel (Arévalo et al., 2010).

An important result, because of this movement, is that near SS4 and SS6, partial isolation from major circulation cells occurs, with all that this means for the purpose of dynamic sedimentary and renewal of water masses. A special case is the case of the SS3, which appears to be in the most important area of sedimentation caused by the dynamics of water currents in the lagoon.

To understand the distribution of these textural classes, it is necessary to understand the processes of entrainment and deposition that occur internally in this lagoon. Thus, according to the pattern of marine currents existing in this lagoon (Díaz del Rio and Somoza, 1993; Bautista et al., 2007) it can be deduced that the internal sampling stations of the Mar Menor with sandy texture, in particular SS2 and SS1 are located in areas preferentially washed by currents that run parallel to the coastline. Thus, the entrainment processes clearly seem to dominate over sedimentation and therefore textures are enriched in sands.

However, some relevant phenomena have been observed in the vicinity of these sampling points that could be indicating information of interest in relation to the dynamics of currents of this coastal lagoon. For this discussion, it must be taken into account that settlement of fine grained suspended sediment is enhanced where mixing of different salt concentration water occurs, but the influence on this shallow area conducted by the wind should be stressed (Perez-Ruzafa et al., 2005; SIOM, 2014). Under these conditions, even slight increases in salinity $(>1 \%)$ will promote the aggregation of fine clay particles. This process is known as flocculation and leads to an increase in grain size and thus in grain settling velocity. Flocculation is a common process in estuarine environments and in salt marshes, and may lead to the development of zones of high turbidity and fine sediment deposition (Perry and Taylor, 2007). This phenomenon has been observed in large areas of shallow water near SS1 and SS2, which seems to suggest that in these areas the depositional dynamics differ slightly from that of the sampling 
stations indicated below. It should be emphasized here that these areas are located just off the mouth of the major ephemeral watercourses draining into the Mar Menor.

In addition, SS5, SS7, SS8 and SS9 located in areas fairly close to the outer shore of the Mar Menor showed a loamy texture. In this case, there seems to be a certain balance between entrainment and deposition processes, except for SS8 where entrainment seems to overcome to deposition. The influence of the currents seems to be moderate, but the sand contribution coming from the sandy strip separating the coastal lagoon from the Mediterranean Sea appears to be important. Therefore, in these areas it can be found an intermediate behaviour between washing and deposition, which is producing a more equitable deposition between fine materials (silt and clay) and coarse (sand). It is interesting to note the case of SS7, next to a water flow between the lagoon and the Mediterranean Sea. According to the water current distribution (Fig. 1), this point should be a washed area (sandy texture). However, possibly due to the construction of dams, it has become a transport area in which the entrainment processes due to the water flow inlet and outlet, and the deposition of fine particles, possibly favoured by the dams, have caused this anomaly.

By contrast, as the entrainment current diminishes the intensity, it will produce a selective deposition of the fine particles, and therefore a relative sand impoverishment of the sediments of these deposition zones. These depositions seem to occur further away from areas of maximum exposure to currents. In the case of the studied sediments, the degree of cohesion of silt and clay was quite small, being mostly poorly coordinated, especially in its most superficial sediment layers. In light of the grain size analysis of surficial samples of the ten considered sampling stations it is observed that silty bottoms, and therefore those with a more sedimentary character, were those which for various reasons seem to be out of the direct flow of water currents, thus acting as deposition areas for finest materials $(<50 \mu)$ carried by them. This would be the case for the SS4 and SS6, but especially in SS3, appearing in these localities a high rate of sedimentation of silt and clay in comparison with the levels found in other stations (Fig. 2), with a relevant presence of clay.

Finally, the case of SS10, also sandy, is different because it is a control station placed outside the lagoon and thus subject to the effect of the stream that runs parallel to the Mediterranean coast (Font, 1987; SIOM, 2014), clearly dominated by sandy sea beds. In any case, it appears that the strength of these currents is large enough to drag the smaller particles to other areas of deposition.

\subsubsection{Mineralogy of sediments}

A basic aspect of characterization of the samples has been the colour of them. This indicated that the colour variation was not too large, varying from grey to light brownish grey and light olive brown, under the Munsell colour keys.

The study by XRD of sediments of different sampling stations generated the data presented in Graph 1. Reflection-microscopy detected the presence of calcite, quartz, aragonite, calcite magnesian, illite, dolomite, sanidine, greenalite, halite and pyrite. All these majority mineral phases found in the samples, except for halite, pyrite and greenalite, are characteristic mineral phases of the general geological setting of the Mar Menor coastal lagoon and the different watercourses that flow into it (Oen et al., 1975). In turn, halite has been considered as a characteristic mineral phase of marine environments.

Regarding pyrite, it is noted that in addition to setting their possible origin in the former mining area of Cartagena-La Union, it is likely that some of this pyritic fraction is of autogenic origin (Simonneau, 1973),

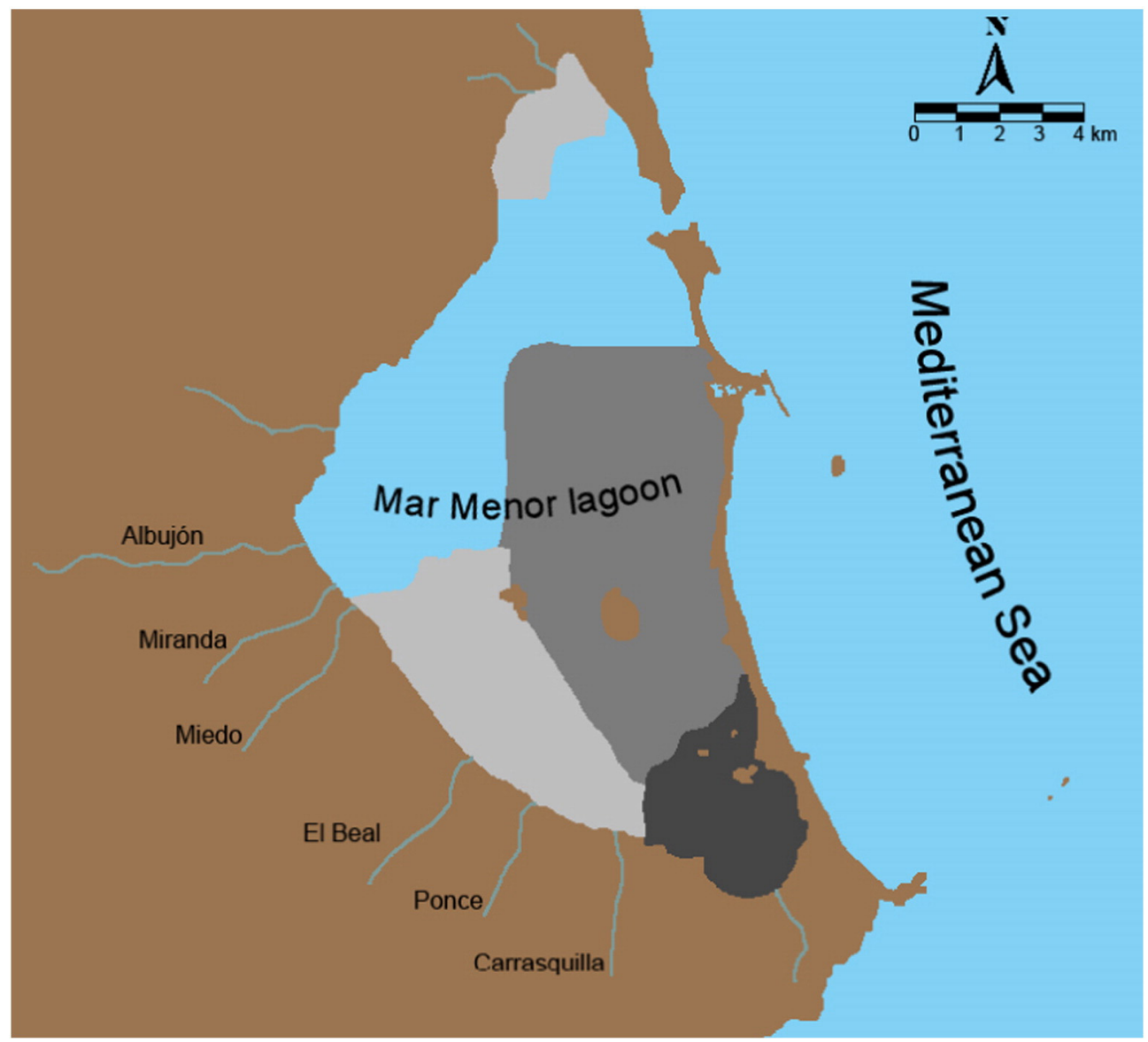

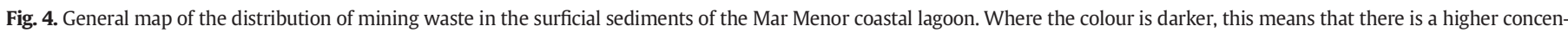
tration of mining sediments. (For interpretation of the references to colour in this figure legend, the reader is referred to the web version of this article.) 


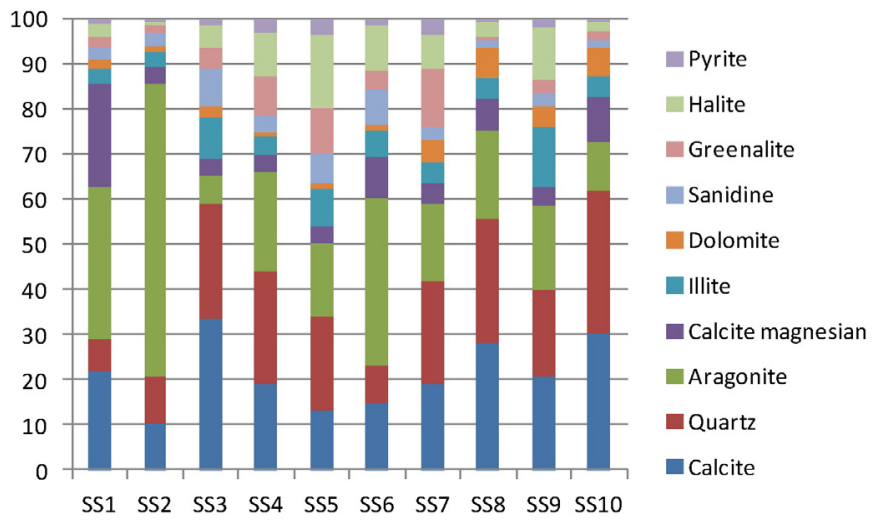

Graph 1. Mineralogical composition of the sediments estimated by XRD (weight \%; semiquantitative estimation on the crystalline fraction) for each sampling station (SS).

so that the interest of this mineral species as an indicator of the mining source is limited.

Finally, greenalite has been considered as a unique and characteristic mineral from the mining district of Cartagena-La Union (Manteca Martinez and Ovejero Zappino, 1992). This mineral is important in metamorphic rocks as a result of hydrothermal alteration of iron and magnesium silicates, such as amphibole, pyroxene and biotite appearing in igneous rocks, especially in ultrabasic rocks. Therefore, the greenalite has been regarded as the indicator mineral for residues from mining area.

Considering the presence or absence of greenalite, it was confirmed the presence, in varying degrees, of mining waste between sediments of different sampling points (Graph 2). Specifically, the percentage of the presence of these tailings were found to be higher in sampling stations located in the eastern part of the lagoon, reaching their maximum concentrations in SS7, SS4 and SS5, and minor in SS3 and SS6. The levels of this mineral phase in the rest of sampling stations proved to be little more than testimonial.

Meanwhile, the other mineral with a predominantly mining origin, which can also come from other sources, is pyrite (Graph 2). In this case, this mineral follows patterns similar to those shown by greenalite, with higher levels in the eastern part of the lagoon, which coincides with the cited for the year 1972 by Simonneau (1973).

These results draw attention to the low level of greenalite and pyrite in the area closest to the point of entry of mining waste in the lagoon (SS2). This appears to be due to the existence of a strong entrainment process in this area, which facilitates the transport and deposition of this mining waste in the most central (SS3) and eastern parts (SS4, SS5 and SS6) of the lagoon. The strong washing of this entry area seems to produce a drag and transport of these mining minerals from the entrance area and subsequent deposition to short and medium

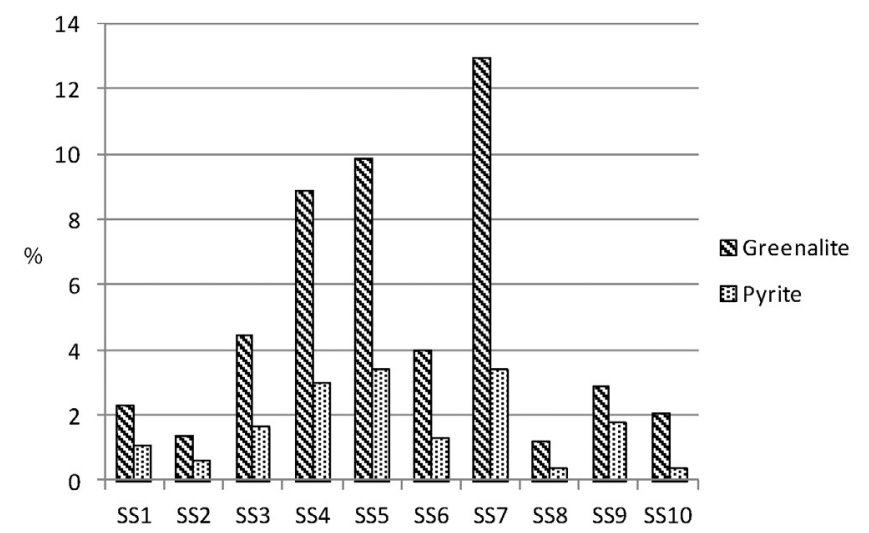

Graph 2. Greenalite and pyrite percentage (\%) in sediments for each sampling station (SS) distances before settling. On the other hand, sampling stations located in the northern part (SS9 and SS6) showed exogenous sediments resulting from the dredging of the seabed in other parts of the lagoon carried out during 1986 or from the use of mining waste for the construction of some infrastructure in coastal areas, which could have increased greenalite levels in these zones.

Concerning other mineral phases, the large presence of aragonite should be mentioned, from mollusc samples from Mar Menor, compared with the control sampling station placed in the Mediterranean (SS10) wherein the concentration of these organisms is much lower. In turn, within the Mar Menor, the high concentration of this mineral in areas characterized by a high concentration of molluscs, especially bivalves, in their beds must be emphasized (Auernheimer et al., 1984). In relation to the magnesium calcite, note its high concentration at the mouth of the wadi Albujón (SS1). These results matched, to a greater or lesser extent, the data expressed by Simonneau (1973).

\subsubsection{Geochemistry of sediments}

On a basic level, the most abundant elements in the sediments studied were $\mathrm{C}, \mathrm{Na}, \mathrm{Mg}, \mathrm{Al}, \mathrm{Si}, \mathrm{S}, \mathrm{Cl}, \mathrm{K}, \mathrm{Ca}$, Fe and $\mathrm{Sr}$. The most characteristic elements of the mining environment are $\mathrm{S}, \mathrm{Fe}, \mathrm{Zn}$ and $\mathrm{Pb}$, primarily because of its association to mineral phases typical of the Sierra de Cartagena-La Union (Manteca Martinez and Ovejero Zappino, 1992).

For these element characteristics from the mining area, higher concentrations generally occurred in SS3, SS4 and SS5, and complementary in SS7, which seems to be indicating a higher concentration of these elements in the eastern and central lagoon (Graph 3). Moreover, for the case of $\mathrm{Pb}, \mathrm{SS} 2$ sediments also have a high concentration of this element, precisely at the point where the discharge of mining sediments occurs in the lagoon through the El Beal rambla. In turn, there were significant concentrations of $\mathrm{S}$ in some sampling stations to the north and west of the lagoon (SS1 and SS9), possibly due to the high mobility of this element. These results are highly consistent with the presence of mining wastes in those sediments presented in the previous section, as well as some previous results for these sampling points. Regarding these previous results which appeared in Dassenakis et al. (2010) Pb, Zn and Fe concentration in sediments followed the same pattern for all the sampling stations, although this similarity was not so high for the case of metals in the water column and molluscs tissues.

Currently, there is not legislation, European or national that helps us to define the maximum permissible metal content for marine and coastal lagoon sediments. Therefore, there is only the Directive 2000/60/EC, in the European context, and the RD 60/2011 on the national level, which relates only to the water quality. Anyway, looking for environmental protection, a possible action could be not to remove the sediments of the most polluted areas of this coastal lagoon, and not to use these materials for other purposes.

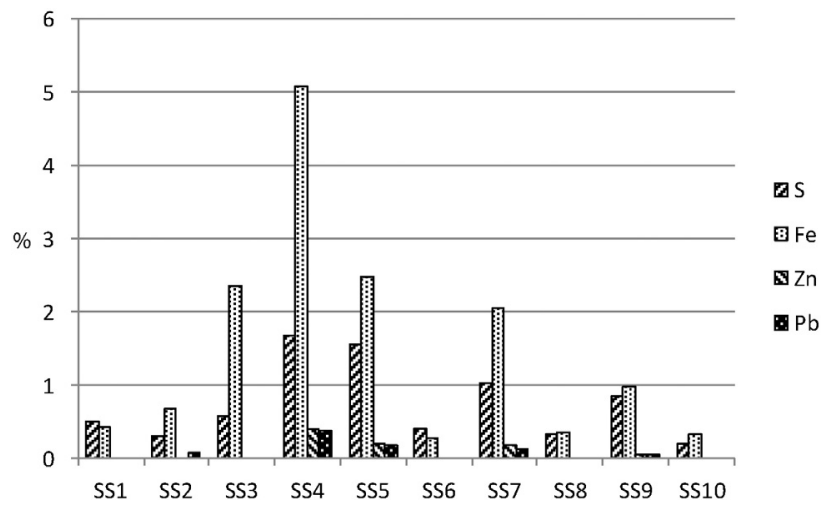

Graph 3. S, Fe, Zn and Pb concentrations (\%) estimated by WDXRF for each sampling station (SS). 
The largest proportion of the contaminant load in sediment systems is transported by suspended particulate matter (Gibbs, 1977). Grain size is possibly the most significant factor controlling the concentration and retention of contaminants in both suspended and bed sediment. Metals in particular have been shown to be enriched in the fine silt and clay fractions of sediments, as a result of their large surface area, organic and clay contents, surface charge and cation exchange capacity. Furthermore, epigenetic (called early diagenetic by some authors) reactions have an impact upon the short and long-term fate of contaminants in sediments through two principal mechanisms: release of contaminants into sediment porewaters and the uptake of contaminants into authigenic mineral precipitates (Rae and Allen, 1993).

\subsubsection{Organic matter}

Early diagenetic, or epigenetic, and bacterially mediated redox reactions, which result in the oxidation of carbon species (organic matter) and the reduction of an oxidized species are the basis of the processes that are acting upon marine sediments. These processes require a long time for specific redox conditions to affect organic matter. In surface samples, as considered here, the influence on the type and amount of organic matter seems to be more related to the dynamics of sedimentation than to epigenetic factors discussed above.

When comparing results of this research with those from 1972 (Simonneau, 1973) it is observed that areas with greater accumulation of organic matter remained the same, although there has been an especially notable increase in the absolute amount of this parameter, with values especially increased in the sedimentation zones (SS3 and SS4). These values of organic matter are high in the north and west, and especially in areas of sedimentation in the central and southern lagoon.

Graph 4 shows the results of thermogravimetric analysis carried out for the 10 sampling stations considered in this study. This graph shows the results relating to the concentrations of organic matter and inorganic $\mathrm{CO}_{2} . \mathrm{H}_{2} \mathrm{O}$ indicated in this graph refers to free water present in the samples at the time of analysis. A high concentration of organic matter is accompanied by an increased presence of organic carbon, while in those places where the concentration of organic matter is low, $\mathrm{C}$ primarily appears as inorganic carbon from the combustion of mollusc shells.

After an analysis of the sampling stations, some patterns have been detected. A series of sampling stations (SS1, SS2, SS8 and SS10) showed relatively low amounts of organic matter occurring. Indeed, these stations of low organic loading are the same as those which are exposed to more intense entrainments, which seems to indicate that this washing affects not only the fine particles of the mineral fraction (silt and clay), but also the organic matter.

Meanwhile, stations that had an increased accumulation of organic matter (SS5, SS9 and SS7) corresponded to the transition zones in the scheme of the lagoon. In this regard, it should be noted that the dynamic

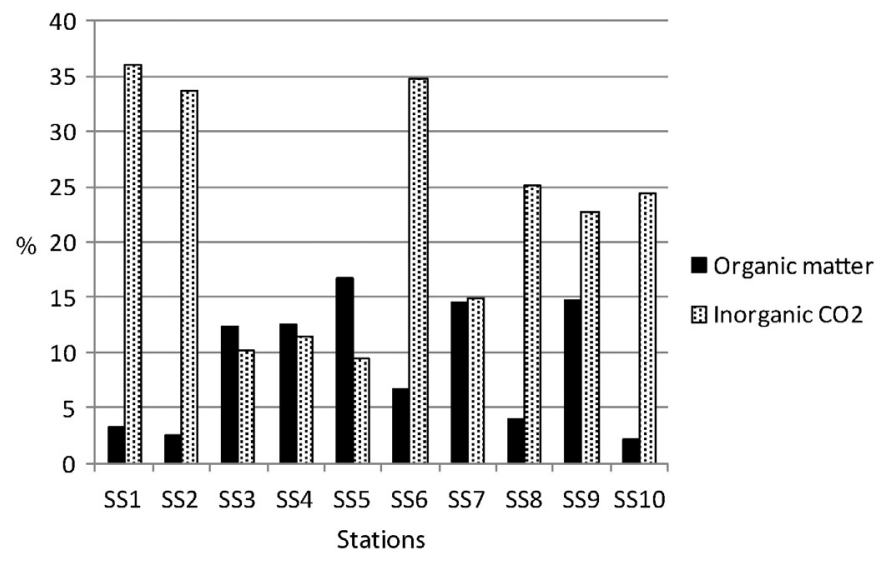

Graph 4. Organic matter and inorganic $\mathrm{CO}_{2}$ concentration (\%) estimated by TG-MS for each sampling station (SS). balance of suspension vs. sedimentation of sedimentary and suspended organic matter is regarded as one of the major factors affecting their spatial distribution (Pusceddu et al., 1999), and these sedimentation patterns are different to those shown by the mineral fractions. Therefore, while mineral fractions settle only in the areas of deposition, the organic fractions appear to be able to settle mainly in areas where currents still have a certain intensity. In this regard, it should be stressed that the points with low carbon and organic matter content correspond to points exposed to strong entrainment by currents and marine dynamics.

Regarding the above, we should consider the case of sampling stations that showed medium levels of organic matter. In this case, the results are consistent with those stations with a predominant sedimentary character for mineral fractions, i.e. SS6, SS3 and SS4. According to the data expressed above, the sedimentation dynamics would not only affect fine sediment fractions (silt and clay) carried by the currents, but also provoke the sedimentation of organic fractions suspended in the water and that have not been previously precipitated.

\subsection{Historical evolution of sediments of the Mar Menor}

There are historical references to some events (Table 1) that have had a strong influence on the dynamics of the beds, as well as the hydrological characteristics of the Mar Menor lagoon (Jiménez de Gregorio, 1957; Pérez-Ruzafa et al., 1987). One of the latter was the one in 1869, possibly reinforced by the construction of an artificial channel of communication with the Mediterranean (the Gola del Charco in 1878), which caused a significant decrease in the salinity of the waters that passed from a $60-70 \%$ o to stabilize around $50-52 \%$ (Navarro, 1927; Lozano, 1954; Pérez-Ruzafa et al., 1987). This significantly changed the lagoon biology with an increase in overall species diversity of the lagoon. Another momentous event was the huge increase in the rate of sedimentation of the Mar Menor as a result of human activities, primarily since 1890 (Pérez-Ruzafa et al., 1987).

Furthermore, the implementation of the Tajo-Segura aqueduct in 1979 that brought water from central to southeastern Spain allowed all agricultural plains surrounding the Mar Menor to be under intensive culture. This marked the entry into the coastal lagoon, formerly an oligotrophic ecosystem, of large quantities of nutrients in the form of fertilizers and agricultural runoff from farmlands. This allowed the implementation of seagrass prairies and increased benthic diversity in a confined environment, which would produce a significant increase in mean maximum concentrations of organic matter in sediments (Pérez-Ruzafa et al., 1987). In turn, another modification with high incidence from the biological point of view was the dredging in the early 1970s of one of the channels of communication with the Mediterranean, El Estacio, for the construction of a marina and a navigable channel.

The increase in the water exchange with the open sea has resulted in a slight easing of extreme temperatures and a marked decrease in salinity that currently appear to have stabilized between $42^{\prime} 75$ and $46{ }^{\prime} 70 \%$. These conditions have favoured the penetration and massive implantations of new species in phytoplankton, fish and shellfish (Pérez-Ruzafa et al., 1987).

When studying the sedimentary evolution of the lagoon, we considered the data generated from three surveys of up to $55 \mathrm{~cm}$ deep. These surveys were conducted in three sampling stations (SS2, SS3 and SS8) located along a transept crossing the Mar Menor southwest to northeast direction. In relation to these surveys, keep in mind that the sedimentation rate estimated for this coastal lagoon is about $30 \mathrm{~cm} /$ century for the period between 1890 until now (Pérez-Ruzafa et al., 1987). On other hand, please note that this rate was much lower ( $40 \mathrm{~mm} /$ century) during the previous period (from the middle age up to 1890). Therefore, the period covered by the studied sediments goes from the late fourteenth century to the present day (Table 1). 
Table 1

Evolution of sedimentary dynamics in three sampling stations of the Mar Menor coastal lagoon.

\begin{tabular}{|c|c|c|c|c|c|c|}
\hline \multicolumn{3}{|c|}{ Sediment texture } & \multirow{2}{*}{$\begin{array}{c}\text { Depth } \\
(\mathbf{c m})\end{array}$} & \multirow{2}{*}{$\begin{array}{l}\text { Time } \\
\text { period }\end{array}$} & \multirow{2}{*}{ Years } & \multirow{2}{*}{ Relevant events } \\
\hline SS 2 & SS 3 & SS 8 & & & & \\
\hline 8008 & & & $0-2$ & $2000-2007$ & 7 & Increase of urban areas and tourism. \\
\hline $\begin{array}{l}808 \\
0008 \\
\end{array}$ & & $\begin{array}{l}908 \\
9000 \\
9000\end{array}$ & $2-5$ & $1990-2000$ & 10 & Increase of urban areas and tourism. \\
\hline & & $\begin{array}{l}90 \\
000 \\
000\end{array}$ & $5-10$ & $1973-1990$ & 17 & $\begin{array}{l}\text { Dredging of the lagoon (1986) and widening of The Estacio } \\
\text { Channel (1974). Open pit mining. Increase of urban areas. }\end{array}$ \\
\hline $\begin{array}{l}80 \\
800 \\
800\end{array}$ & & $\because \because$ & $10-15$ & $1956-1973$ & 17 & $\begin{array}{l}\text { Home of mining at big scale and open pit mining. Increase } \\
\text { of urban areas and tourism. }\end{array}$ \\
\hline & & & $15-20$ & $1939-1956$ & 17 & No relevant events \\
\hline 8091 & & $\begin{array}{l}800 \\
000 \\
0.00\end{array}$ & $20-25$ & 1922-1939 & 17 & No relevant events \\
\hline & $\because \because \because$ & $\because \because \because$ & $25-30$ & $1905-1922$ & 17 & No relevant events \\
\hline & & & $30-35$ & $1890-1905$ & 15 & $\begin{array}{l}1890 \text { Significant increase in the rate of sedimentation in the } \\
\text { Mar Menor (from } 4 \text { to } 30 \mathrm{~cm} \text { every } 100 \text { years). }\end{array}$ \\
\hline & & $\begin{array}{l}800 \\
8000 \\
6000 \\
8000 \\
0000 \\
0000\end{array}$ & $35-40$ & $1765-1890$ & 125 & $\begin{array}{l}\text { Increase of crops and opening of new wells for land } \\
\text { irrigation. } 1878 \text { Dredging and opening of El Charco } \\
\text { channel. }\end{array}$ \\
\hline & & 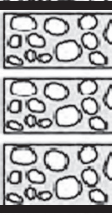 & $40-45$ & $1640-1765$ & 125 & 1762 Dredging and opening of Constancia channel. \\
\hline & & 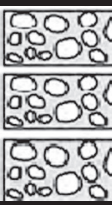 & $45-50$ & $1515-1640$ & 125 & Deforestation and ploughing of land. \\
\hline & & & $50-55$ & $1390-1515$ & 125 & Pasturage and ploughing of land. \\
\hline & Depositic & processes & & $\because \because \because \cdots$ & port proc & 8080 \\
\hline
\end{tabular}

\subsubsection{Variation of texture of the sediments}

In the southwest area of the lagoon is located SS2, close to the mouth of a seasonal river with important contributions of mining waste. Here, the predominant texture has historically been clayey until the early twentieth century when this varied to sandy (Table 1 ). This period seems to show the effects of events that happened in previous years, such as the opening of the Gola del Charco, along with an intensification of plowing and tillage. These actions and the intensification of mining activity in the Mining District of Cartagena-La Union could be the cause of the change of the sedimentary character of this area over time, changing this character from a sedimentation zone to a washing area in the early twentieth century.

Meanwhile, in the central area of the lagoon is located SS3. Here, the area has historically presented a distinctly sedimentary character, with a predominantly silty texture, except for the period between 1905 and 1956 which showed a significant increase in the sand fraction (Table 1). This behaviour seems to agree with the data manifested in SS2, although this central area of the lagoon, SS3, after a period of 50 years, returned to reestablish its historical dynamics as a typically sedimentary area.
SS8 is placed in the northeast of the lagoon, where another deep survey was carried out. Here, during the time period considered, this area was exposed to a continuous washing dynamic that was interrupted, as in the two previous cases, in the early twentieth century as a result, predictably, of the same facts that determined the change in the southern zone (SS2) and central (SS3) of the lagoon. After this initial disruption of a transitional type, SS8 regained its character as a washing area, with another short break during the mid-twentieth century in which it again acted as a transport zone. This area, over the last decade, experienced a variation of its sedimentary character in order to become a zone of sedimentation (Table 1). Therefore, this north part of the lagoon can be considered as a very stable area over the studied period, where there have only been some changes in sediment dynamics recently. These changes seem to be due to a possible change in coastal dynamics by human actions, such as building dams or ports in the nearest urban areas during the last decades.

In relation to all this data of the sedimentary series of the lagoon, few references, and even less matching cases, are available for the same sampling areas. Regarding textural distribution it should be noted that 
during 1972 several samples were collected (Simonneau, 1973) in order to assess, among other things, the grain size distribution in these beds of the coastal lagoon. Since then, extensive engineering activities have been conducted. These activities have significantly affected the lagoon beds, both directly by dredging them (year 1986) and indirectly by opening large water channels between the coastal lagoon and the Mediterranean Sea (year 1974) (Pérez-Ruzafa et al., 1987). On the other hand, the contribution of mining waste has been constant during this time, especially through the ramblas that flow from the mining area into the Mar Menor. Accordingly, it may be of interest establishing a comparison of 1972 sampling data with data generated in the present study 35 years later.

For several points, such as SS3, but to a lesser extent also SS1, SS2 and SS9, there is available data about grain size distribution for different periods of time (Simonneau, 1973; Marín-Guirao et al., 2005). For all these cases, when one compares the values generated in this research with others that appear in former studies, particle size distribution are, more or less, coincident.

In any case, it is remarkable in light of the historical period considered, that since the fourteenth century to the early twentieth century, the sedimentary behaviour of the lagoon seemed to be stable, with washing areas (SS8) and sedimentary zones (SS2 and SS3). Since then, and possibly because of anthropogenic causes, the sedimentary dynamics within the lagoon varied very significantly, so that historically sedimentary areas (SS2) became washing areas on a permanent basis. In turn, other areas that until the early twentieth century showed defined dynamics (sedimentary for SS3, and entrainment for SS8) regained their traditional sedimentary dynamics after a few decades, in a more or less stable way. This higher or lesser stability could be highly influenced by the proximity of each site to areas under human influence (modification of the seabed, infrastructure construction, etc.).

\subsubsection{Mineral evolution of the sediments}

The mineral analysis of the three conducted surveys showed different behaviours depending on the considered mineral phase (Graphs 5, 6 and 7). So, the calcite highlighted in SS8 showed percentages above $20 \%$ throughout the entire time period (Graph 7). Meanwhile, in the other two sampling points, there have been variations in the historical presence of this mineral, variations that can be considered important for SS3 (Graph 6) and not so remarkable for SS2 (Graph 5).

Quartz showed a very similar dynamic to that of calcite. This mineral is associated with silica sands, which dominated the SS8 profile and to a lesser extent the profile of the SS3, which shows us the nature of the substrate consisting essentially in silica sands, as opposed to what happened with SS2, which reinforced the idea of the mining origin of the sediments of SS2. In the case of aragonite, it must be taken into account that this mineral is mainly associated with the remains of shells of molluscs. Thus, it is noteworthy the case of SS2, whose wealth in this

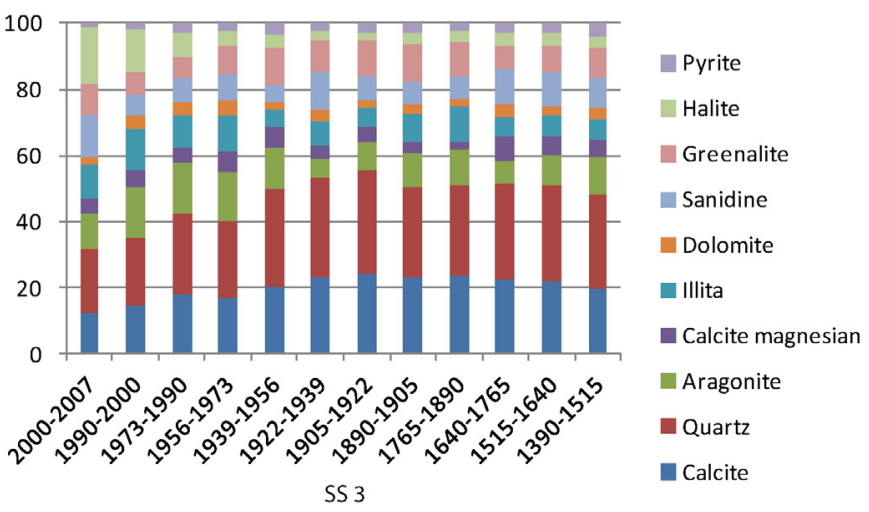

Graph 6. Mineral evolution of the sediments for SS3 estimated by XRD (weight \%; semiquantitative estimation on the crystalline fraction).

mineral is overwhelming in both surface and depth analysis, which seems to indicate the extraordinary wealth of biogenic remains of molluscs at this point, whether originating from this area or dragged and deposited from other areas. This fact could be related to aspects such as dynamics of the internal currents of the lagoon and productivity of shellfish in different areas of the Mar Menor, aspects that seem to favour the accumulation of the remains of these animals in the southern part of the lagoon. Therefore, in relation to this major mineral, the relative wealth of aragonite seems to be determining the mineralogical structure of the southern part of the lagoon (SS2). This huge dominance of aragonite makes the mineralogy of this point noticeably different from that presented in the central zone (SS3) and north (SS8), resulting in a relative impoverishment of other mineral phases (calcite, quartz) in SS2, phases that are relatively more abundant in the rest of the lagoon.

Among the remaining minerals, it must be highlighted that the magnesium calcite, such as illite, dolomite, sanidine and halite is present in small percentages, without a distinct and clear pattern between different locations.

Meanwhile, pyrite, a mineral mainly linked to the mining area, has relatively low levels but with important differences between areas. Regarding this, higher levels have been found in the central part (SS3) and to a lesser extent in the southern part (SS2), while in the north part (SS8) this mineral was almost non-existent. In the nearest survey to the mining zone (SS2) it has been able to prove the existence of more or less constant values, although low, remarkable in that a slight increase coincided temporarily with the textural changes observed in the period 1905-1922. Remember that at this station the entrainment processes are very high, so these low values are understandable. Furthermore, in the sedimentation zone located in the centre of the

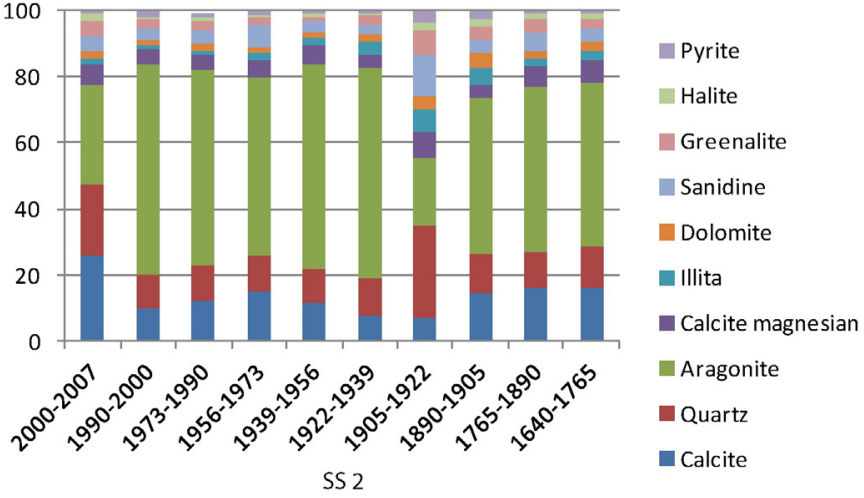

Graph 5. Mineral evolution of the sediments for SS2 estimated by XRD (weight \%; semiquantitative estimation on the crystalline fraction).

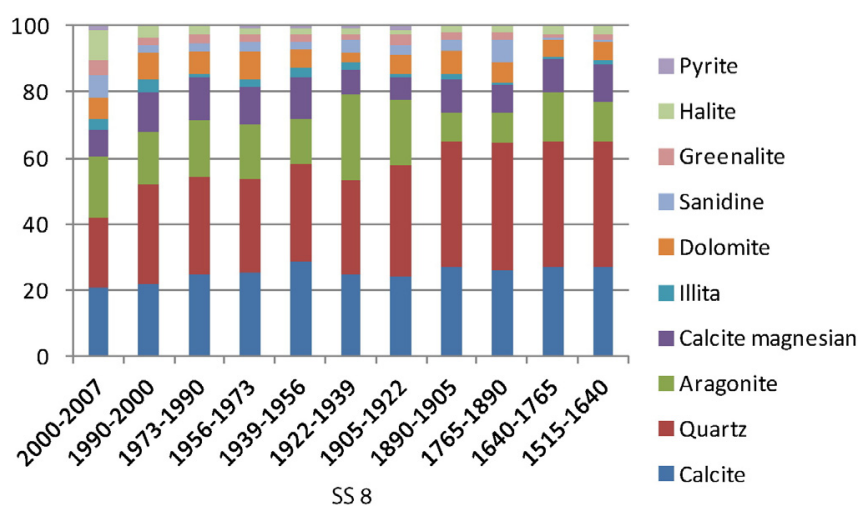

Graph 7. Mineral evolution of the sediments for SS8 estimated by XRD (weight \%; semi-quantitative estimation on the crystalline fraction). 
lagoon (SS3) the highest values of the mineral were observed, although it is quite possible that some of this pyritic fraction has an authigenic origin. At the station further north, and therefore further from the mining area, pyrite values are the lowest found throughout the considered profiles, something expected and matched by low levels of $\mathrm{S}$ and $\mathrm{Fe}$ expressed for this area in previous studies (Simonneau, 1973).

In relation to greenalite, which is the mineral that has been specifically used as an indicator of mining sediments, it showed a distribution through profiles with some similarity to pyrite patterns. In this regard, its levels are relatively high in the central part (SS3, Graph 6) and to a lesser extent in the southern part (SS2, Graph 5), while the northern part (SS8, Graph 7) showed almost zero level for this mineral, except in the most superficial part $(0-2 \mathrm{~cm})$. This anomaly for SS8 could be caused by the construction of some infrastructure in coastal areas close to this point, where were used, at least partially, some waste from the mining area. In the nearest survey to the mining zone (SS2) it has been able to prove the existence of low values and more or less constant, with some peaks coinciding with the textural change observed in this area during the period 1905-1922, which also happened to pyrite. It must be remembered that at this station the entrainment processes have been very high during the considered period. Furthermore, the highest sedimentation rate was located in the middle of the lagoon (SS3). Similarly, the values found in the profile of SS8, which is the farthest from the mining area station, are the lowest of those found throughout the studied profiles, something expected and matched with low levels of elements typical from metal mining expressed for this area in previous studies (Simonneau, 1973).

By studying the patterns of temporal accumulation of the main mineral considered as an indicator of waste from the old mining district of Cartagena-La Union, a differential behaviour was observed, according to the sampling station (Graph 8). In the case of the station located in the southwest (SS2), closest to the mining area, a historic increase was observed from the period 1640 to 1765 . This increase culminated with a peak in the period from 1905 to 1922, coinciding with the change of sedimentary dynamics at this point, that at this time changed from a sedimentation zone to an entrainment area (Table 1). Meanwhile, in the case of the station at the centre point of the lagoon (SS3), the accumulation of this mineral corresponds to its eminently sedimentary character, presenting high rates of accumulation of these materials throughout the period considered, with two points of minimum concentration during the periods 1640-1975 and 1973-1990. Again, a period of high sedimentation rate between the late nineteenth and early twentieth century was observed. Finally, the sampling station located at the north part of the lagoon (SS8) showed a very poor accumulation of these minerals. This point showed only a small peak of accumulation at the beginning of the twentieth century, which also coincides with a change in sediment dynamics, and with a greater peak at the

\section{Greenalite}

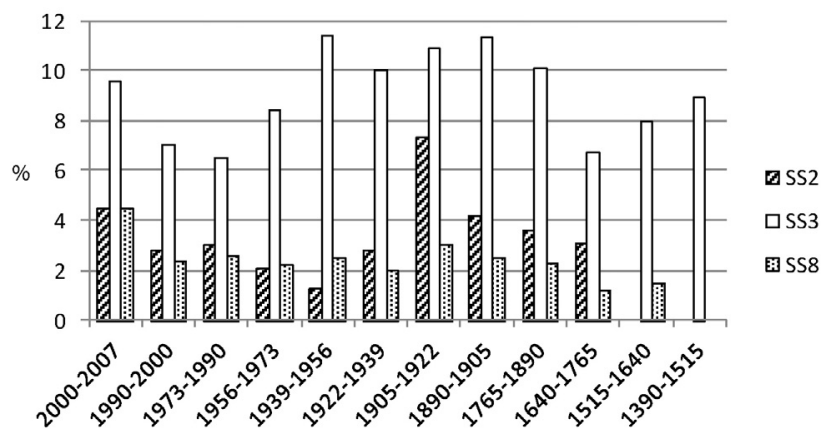

Graph 8. Evolution of greenalite content (\%) in the sediments of sampling stations (SS) situated in the southern (SS2), centre (SS3) and northern (SS8) part of the Mar Menor coastal lagoon.

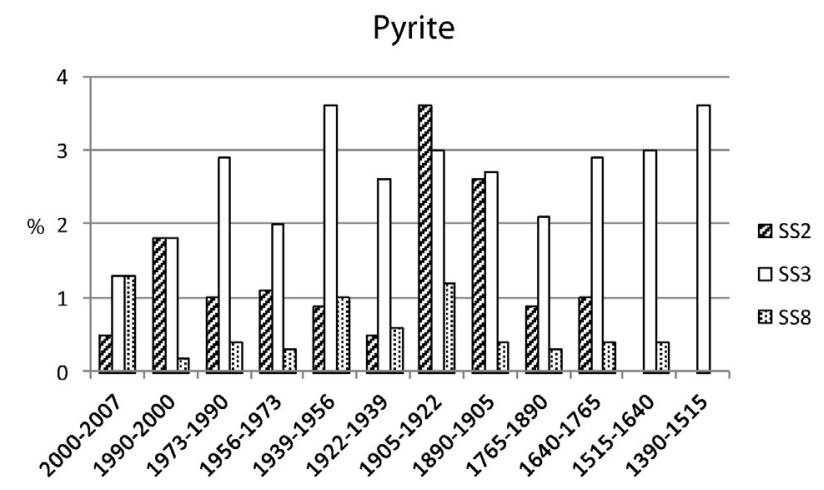

Graph 9. Evolution of pyrite content (\%) in the sediments of sampling stations (SS) situated in the southern (SS2), centre (SS3) and northern (SS8) part of the Mar Menor coastal lagoon.

beginning of the twenty first century, possibly due to the use of mining waste for construction of some infrastructures.

Regarding pyrite, the sedimentation pattern of the mineral has been similar to greenalite, although on a much smaller scale (Graph 9).

\subsubsection{Geochemical evolution of the sediments}

The analysis of the temporal evolution of the presence of the characteristic elements from the mining area ( $\mathrm{S}, \mathrm{Fe}, \mathrm{Zn}$ and $\mathrm{Pb}$ ) was conducted in the three deep surveys made in SS2, SS3 and SS8.

When comparing the different sampling stations it can be observed once again a more moderate concentration in the southwest part (SS2, Graph 10) compared to the high accumulation of these elements in the middle of the lagoon (SS3, Graph 11), and even less in the north area (SS8, Graph 12).

Regarding the temporal trend for the concentration of the elements considered, highlight the historical evolution of the concentration of metals in the different layers of sediments studied, which was very similar to that shown in the three studied sampling stations for greenalite, except for the last 4 decades for SS2 and SS3. This small difference does not seem to be related exactly to the phases of sedimentation, or textural changes observed, nor to the mineralogical evolution observed. The presence of peaks in the distribution of these elements may be related more to intensity and methods of exploitation of metallic minerals carried out at each time.

Thus, the SS2 greenalite maximum peak observed in the period from 1905 to 1922 corresponds to the maximum presence of Fe and S, but not for $\mathrm{Pb}$ and $\mathrm{Zn}$ whose values were low during this period. This fact may be due, probably, to selective element extraction at that time by the mining industry, because of market requirements.

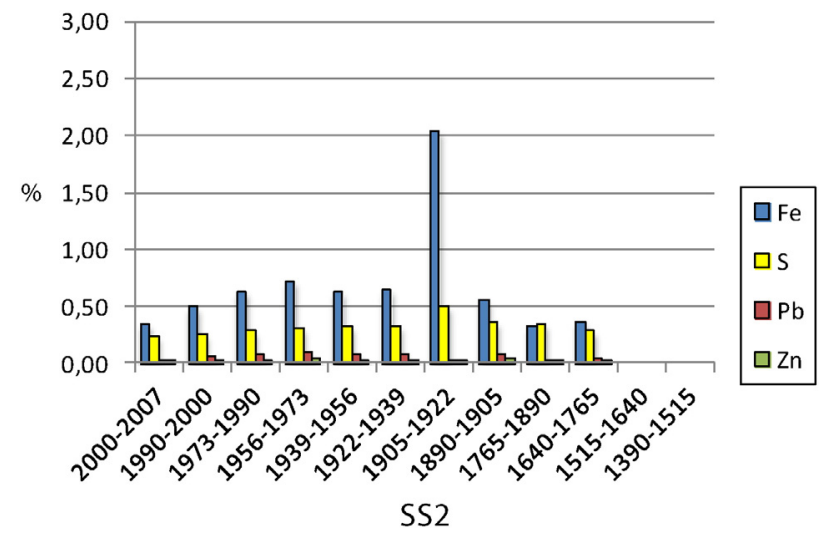

Graph 10. Evolution of Fe, S, Zn and Pb content (\%) for SS2 estimated by WDXRF. 


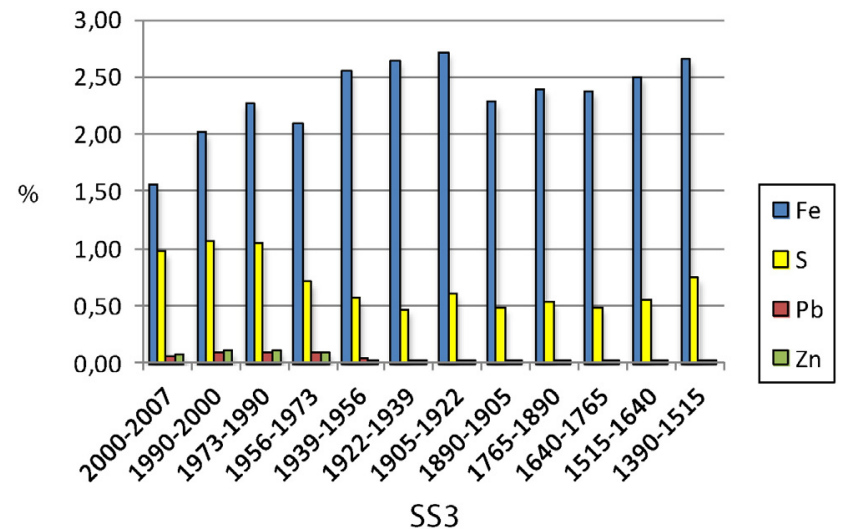

Graph 11. Evolution of Fe, S, Zn and Pb content (\%) for SS3 estimated by WDXRF

In the case of SS3, different metals showed a very similar pattern to that shown in SS2, albeit with much higher concentration values, which corresponds to its historically sedimentary character.

As to SS8, the concentration values are always very low, but show the presence of background levels constant throughout the time series, only distorted by some notable increases over recent years, as occurs with greenalite. These increases may be due not to the traditional causes of dispersal and marine redistribution of these mining sediments along the lagoon, but rather to anthropogenic factors like building infrastructure in these areas with materials from, at least partially, the mining waste deposits.

\subsubsection{Evolution of the organic matter of the sediments}

The results of organic matter analysis are stating that the levels of organic matter are, and have historically been very low in sediments of SS2 (next to the mining area, Graph 13). On the other hand, these levels have been very high in SS3 (centre of the lagoon, Graph 14), and historically low but higher in recent times in SS8 (north of the lagoon, Graph 15).

By observing the results of thermogravimetric analysis in the sampling points taken from different areas of the Mar Menor lagoon, differences have been observed in the concentrations of organic matter, and organic and inorganic $\mathrm{CO}_{2}$ at different points. A high concentration of organic matter is accompanied by an increased presence of organic carbon, while in those places where the concentration of organic matter is less, the $\mathrm{C}$ appears primarily in his inorganic form coming from mollusc shells.

On the other hand, some trends are observed for each location when comparing the time variation for the three considered sampling stations. Thus, in the SS2, which is next to the downloading area of mining waste, organic matter levels remain low and roughly constant along the

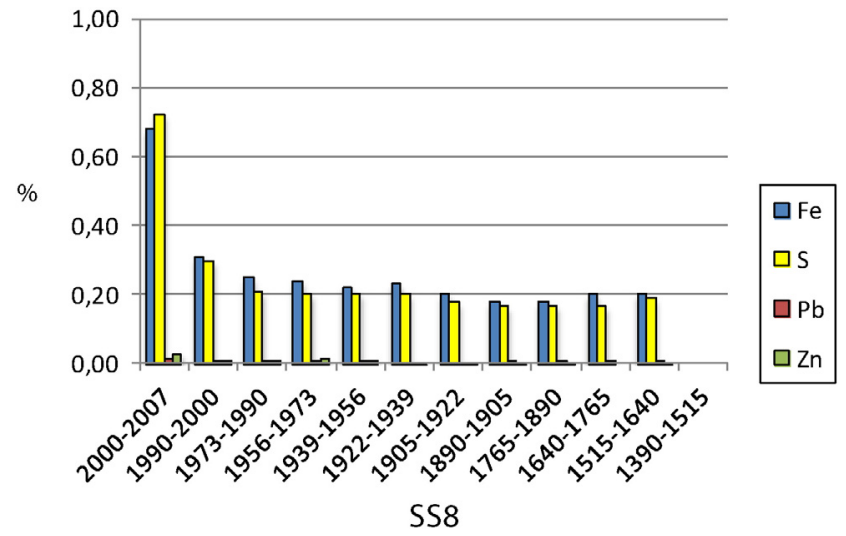

Graph 12. Evolution of Fe, S, Zn and Pb content (\%) for SS8 estimated by WDXRF.

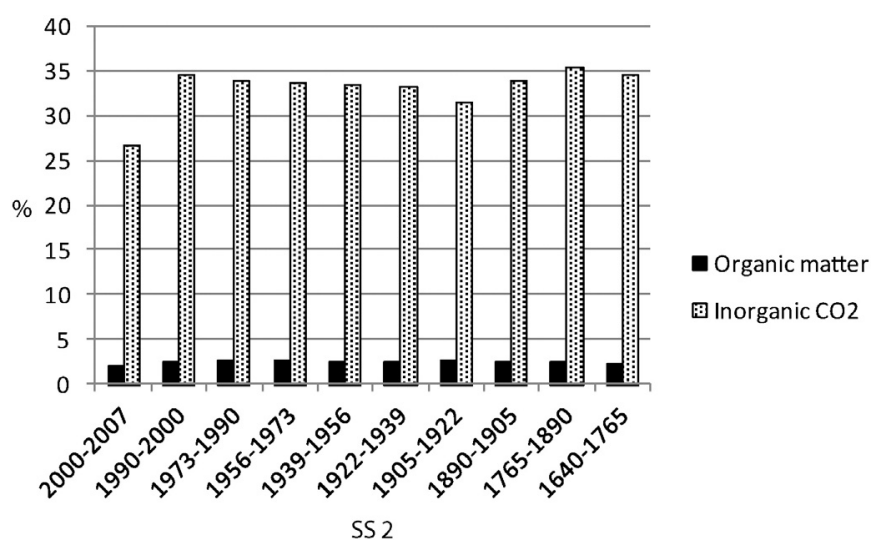

Graph 13. Evolution of organic matter and inorganic $\mathrm{CO}_{2}$ content (\%) for SS2 estimated by TG-MS.

sediment profile. At the station located at the midpoint of the lagoon (SS3), these levels are relatively high with a declining trend up to a depth of about $30 \mathrm{~cm}$, from where another small increase occurs in their values. Finally, in the sampling station placed furthest from the mining area low levels of organic matter and carbon were observed for all the profile, except the first centimetres, which once again could be due to anthropic actions.

By analysing the evolution of organic matter in sediments, none pattern has been detected directly related to the sedimentary phase. In this regard, it has been observed only an increased accumulation of organic matter in recent sediments, compared to a historical accumulation that can be considered low, especially in SS2 and SS8. For the higher accumulation area, SS3, and for SS8, it was detected an increase in the presence of organic matter, especially from the 1970s, when intensive agriculture produced a notable increase in crop lands surrounding the lagoon. This trend was not observed in SS2, probably as a result of major entrainment processes that this sampling station suffered during this period.

Therefore, the clear correlation that occurs for surficial sediments between sediment dynamics and organic matter content is not observed when these sediments are deeper and have been accumulated for longer periods. Moreover, as a remarkable fact, the observed change in recent times in this series of samples relating to organic matter content clearly indicates ecological changes experienced by this lagoon since the second half of the twentieth century, due to the increase of human population and productive activities, mainly agriculture.

\section{Conclusions}

The Mar Menor is a coastal lagoon with a complex internal dynamic, with an average water renewal period of approximately 0.79 years and

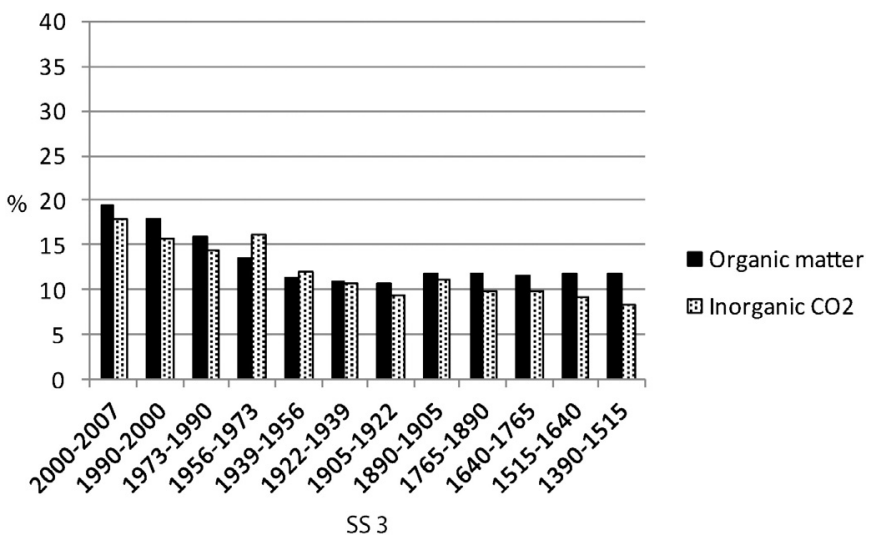

Graph 14. Evolution of organic matter and inorganic $\mathrm{CO}_{2}$ content (\%) for $\mathrm{SS} 3$ estimated by TG-MS. 


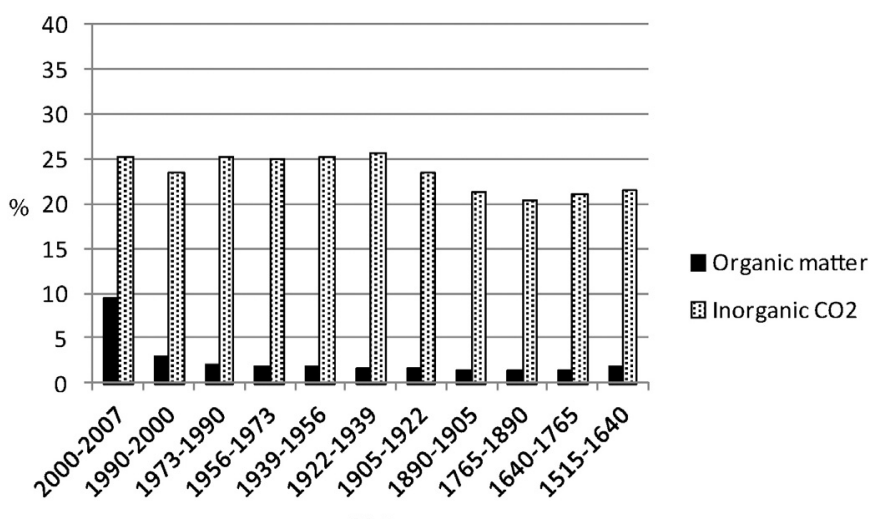

SS 8

Graph 15. Evolution of organic matter and inorganic $\mathrm{CO}_{2}$ content (\%) for SS8 estimated by TG-MS.

a circulation system conducted by several factors. As a result of this redistribution of sediments, remarkable changes in mineralogy and geochemistry occur. At this point, it should be taken into account that the ancient mining district of Cartagena-La Union, located on the southern shore of the Mar Menor, is one of the main sources of sediment supply to this coastal lagoon.

Grain size is an important parameter both from a descriptive perspective and in order to understand sediment transport and deposition. According to the pattern of marine currents existing in this lagoon (Díaz del Rio and Somoza, 1993; Bautista et al., 2007), it can be deduced that the internal sampling stations of the Mar Menor with sandy texture, in particular SS2 and SS1 are located in areas preferentially washed by currents that run parallel to the coastline. Thus, the entrainment processes clearly seem to dominate over sedimentation, which produce sediments enriched in sands, something that also occurs for SS10, the control sampling station placed in the Mediterranean Sea. A different case is that of the areas where there seems to be a certain balance between entrainment and deposition processes (SS5, SS7, SS8 and SS9). The influence of the currents seems to be moderate and, on the other hand, the sand contribution coming from the sandy strip separating the coastal lagoon from the Mediterranean Sea appears to be important. Finally, when the entrainment current diminishes the intensity, it produces a selective deposition of the fine particles, and therefore a relative fine material enrichment of the sediments of these deposition zones. These depositions seem to occur further away from areas of maximum exposure to currents, SS4 and SS6, but especially in SS3.

The study by XRD of sediments from different sampling stations showed that the mineral composition of these sediments was formed by calcite, quartz, aragonite, calcite magnesian, illite, dolomite, sanidine, greenalite, halite and pyrite. All these majority mineral phases found in the samples, except for halite, pyrite and greenalite, are characteristic mineral phases of the general geological setting of the Mar Menor coastal lagoon and the different watercourses that flow into it. Greenalite has been considered as the most characteristic mineral from the mining district of Cartagena-La Union found in the studied sediments, and it has been regarded as the indicator mineral for residues from mining areas. As the presence of greenalite was confirmed, in varying degrees, this indicated to us how important mining wastes were in the sediments of different sampling points. Specifically, the percentage of presence of these tailings were found to be higher in sampling stations located in the eastern part of the lagoon (SS7, SS4 and SS5, and less in SS3 and SS6). The levels of this mineral phase in the rest of sampling stations proved to be little more than testimonial.

These results show the low level of greenalite in the area closest to the point of entry of mining waste into the lagoon (SS2). The strong entrainment of this entry area seems to produce a drag and transport of these mining minerals from the entrance area and subsequent deposition to short and medium distances before settling in the most central
(SS3) and eastern parts (SS4, SS5 and SS6) of the lagoon. The presence of this mineral should be noted, during the last decades, in sampling stations located in the northern part (SS9 and especially SS6). This may be a consequence of the deposition of exogenous materials, coming from the dredging of the seabed in other parts of the lagoon carried out during 1986 or the use of mining waste for construction of some infrastructure in coastal areas, which could have increased greenalite levels in these areas.

Among studied elements, the most characteristic for mining waste are $\mathrm{S}, \mathrm{Fe}, \mathrm{Zn}$ and $\mathrm{Pb}$, primarily because of its association to mineral phases typical from the Sierra de Cartagena-La Union. For these elements characteristics from the mining area, higher concentrations generally occurred in SS3, SS4 and SS5, and complementary in SS7, which seems to be indicating a higher concentration of these elements in the eastern and central areas of the coastal lagoon. These results are highly consistent with the presence of mining waste from lake sediments presented above.

In surficial samples, as considered here, the influence on the type and amount of organic matter seems to be more related to the dynamics of sedimentation than to epigenetic factors. When comparing results of this research with those from 35 years earlier, there has been no variation for areas with greater accumulation of organic matter, although there has been an especially notable increase of this parameter, with values especially increased in the sedimentation zones (SS3 and SS4). These values of organic matter are high in the north and west, and especially in areas of sedimentation in the central and southern lagoon. Regarding the existence of patterns, it was observed that sampling stations of low organic loading (SS1, SS2, SS8 and SS10) are the same as those exposed to more intense entrainments. Sampling stations with higher contents of organic matter (SS5, SS9 and SS7) coincide with the transition zones or sediment transport in the scheme of the lagoon, and finally sampling stations with average organic matter content (SS6, SS3 and SS4) are consistent with those stations with a predominant sedimentary character for mineral fractions. According to these results, it can be concluded that currents and water flows within the lagoon, must be affecting the dynamic balance of suspension vs. sedimentation of sedimentary and suspended organic matter.

As a summary of all these results, Fig. 4 represents a general map of the contribution of mining sediments to the surficial sediments of different parts of the Mar Menor coastal lagoon. This compendium is a joint representation of minerals and metals coming from the mining area, such as greenalite, pyrite, $\mathrm{Pb}, \mathrm{Zn}, \mathrm{Fe}$ and $\mathrm{S}$. Therefore, this map is useful in order to obtain a practical representation of the surficial contamination degree of the Mar Menor coastal lagoon by metal mining waste.

There is not European or national legislation that helps us to check the compliance values of heavy metals with environmental legislation. Besides, no environmental protection actions have been undertaken for solving these problems. Nevertheless, as a recommendation, it could be concluded that the sediments of the most polluted areas of this coastal lagoon should not be removed. It means that some practices that have been done in previous years, such as the dredging of the seabed in some parts of the lagoon to be deposited in others, or the use of mining waste for the construction of some infrastructure in coastal areas, should be abandoned.

Regarding historical evolution of sediments of the Mar Menor since the fourteenth century up to today, there are historical references to some events. The huge increase in the rate of sedimentation of the Mar Menor is a result of human activities. Such as, the implementation of an aqueduct in 1979 that brought water from central Spain allowed increasing intensive agriculture in all the plains surrounding the Mar Menor, which had a strong influence on the dynamics of the beds, as well as the hydrological characteristics of the Mar Menor lagoon.

It is remarkable in light of the historical series considered, that since the fourteenth century to the early twentieth century, the sedimentary 
behaviour of the lagoon seemed to be fairly stable, with clear washing areas (northeast) and clear sedimentary zones (southwest and centre). From this time, and possibly because of anthropogenic causes, the sedimentary dynamics within the lagoon varied in a meaningful way, so that historically sedimentary areas (southwest) became washing areas on a permanent basis. In turn, other areas that until the early twentieth century showed defined dynamics (sedimentary for centre, and entrainment for northeast) regained their traditional sedimentary dynamics after a few decades, in a more or less stable way. This higher or lower stability could be highly influenced by the proximity of each site to areas under human influence (modification of the seabed, infrastructure construction, etc.).

Relating to the evolution of mineralogy of sediments, the mineral analysis showed different behaviours depending on the considered area and mineral phase. Therefore, calcite prevailed in northeast, and aragonite, a mineral mainly associated with the remains of shells of molluscs, appeared to be dominant in the southwest. Finally, in the central part of the lagoon quartz and greenalite showed higher concentrations in comparison to other areas of the Mar Menor. Greenalite, which is the mineral that has been specifically used as an indicator of mining character of the sediments, has presented a behaviour highly related to sedimentation dynamics. This mineral has shown high levels in the central part (SS3) and to a lesser extent in the southwest part (SS2) while the northeast part (SS8) showed almost zero levels for this mineral, except for the last decade. This anomaly for northeast could be caused by the construction of some infrastructure in coastal areas close to this point, where some mining waste was used, at least partially. For all the surveys, some variations have been observed in their profiles, relating to changes in sediment dynamics and with anthropogenic causes.

Results concerning historical evolution of geochemistry of sediments, in particular those of characteristic elements of mining waste $(\mathrm{S}, \mathrm{Fe}, \mathrm{Zn}$ and $\mathrm{Pb}$ ), agreed with the mineralogy and grain size distribution studies, showing, one more time, a behaviour highly related to sedimentation dynamics. When comparing different sampling stations it can be observed, once again, an increased accumulation of these elements in the middle of the lagoon (SS3), compared to a more moderate concentration in the southwest part (SS2) and even more reduced in the northeast area (SS8). For all the surveys, some variations have been observed in their profiles, a fact that can relate, once again, to changes in sediment dynamics and human activities.

In relation to the historical variation of organic matter results stated, basically, that the levels of organic matter have historically been very low in sediments of southwest (SS2, next to the mining area), very high in the centre of the lagoon (SS3) and historically low, but higher in recent times, in northeast (SS8). By analysing the evolution of organic matter in sediments since the fourteenth century, there has not been detected a pattern directly related to the sedimentary phase. In this regard, it has been observed only an increased accumulation of organic matter in recent sediments, compared to a historical accumulation, especially in central areas from the 1970's, when intensive agriculture had a notable increase in croplands surrounding the lagoon. Therefore, the clear correlation that occurs for surficial sediments between sediment dynamics and organic matter content is not observed when these sediments are deeper and have been accumulated for long periods. Moreover, as a remarkable fact, the observed change in recent times in this series of samples in relation to organic matter content clearly indicates ecological change experienced by this lagoon since the second half of the twentieth century, basically due to the increase of human population and of agriculture, as well as other human activities.

\section{Acknowledgments}

The authors would like to thank Fundación Séneca for funding the project $12038 / \mathrm{PI} / 09$. In addition, they want to acknowledge the cooperation of J.M. Peñas, R. Baños, J. Saura, M. Saura and B. Villaescusa who helped us to improve this research and to Mr. and Mrs. Purves for their English grammar supervision.

\section{References}

Abdallah, M.A.M., Mohamed, A.A., 2015. Assessment of heavy metals by sediment quality guideline in surficial sediments of Abu Qir Bay southeastern Mediterranean sea, Egypt. Environ. Earth Sci. 73, 3603-3609. http://dx.doi.org/10.1007/s12665-0143646-2.

Alcolea, A., Ibarra, I., Caparrós, A., Rodríguez, R., 2010. Study of the MS response by TG-MS in an acid mine drainage efflorescence. J. Therm. Anal. Calorim. 101, 1161-1165. http://dx.doi.org/10.1007/s10973-009-0556-8.

Arévalo, L., 1988. El Mar Menor como sistema forzado por el Mediterráneo. Control hidráulico y agentes fuerza. Bol. Inst. Esp. Oceanogr. 5, 63-95.

Arévalo, L., Mas, J., Cestino, J.M., Guerrero, J., 2010. El Mar Menor: Procesos Físico Oceanográficos. Instituto Español de Oceanografía (Publicaciones del Centro Territorial de Murcia 45 pp.).

Auernheimer, C., Llavador, F., Pina, J.A., 1984. Chemical minority elements in bivalve shells. A natural model (Mar Menor, Spain). Archives Des Sciences Geneve 37 pp. 317-331.

Bautista, E.G., Sánchez-Badorrey, E., Díez-Minguito, M., Losada, M.A., Baraza, F., 2007 Modelo de gestión integral del Mar Menor (I): modelo de circulación de la laguna y tramo litoral próximo. IX Jornadas Españolas de Costas y Puertos, San Sebastián, Spain.

Bilkovic, D.M., Roggero, M.M., 2008. Effects of coastal development on near shore estuarine nekton communities. Mar. Ecol. Prog. Ser. 358, 27-39. http://dx.doi.org/10. 3354/meps07279.

Chapman, P.M., Wang, F., 2001. Assessing sediment contamination in estuaries. Environ. Toxicol. Chem. 20, 3-22. http://dx.doi.org/10.1897/1551-5028(2001)020<0003: ASCIE $>2.0 . C O ; 2$.

Courrat, A., Lobry, J., Nicolas, D., Amara, R., Lepage, M., Girardin, M., Le Pape, O., 2009 Anthropogenic disturbances on nursery function of estuarine areas for marine fish species. Estuar. Coast. Shelf Sci. 81, 179-190. http://dx.doi.org/10.1016/ j.ecss.2008.10.017.

Dassenakis, M., Garcia, G., Diamantopoulou, E., Girona, J.D., Garcia-Marin, E.M., Filippi, G., Fioraki, V., 2010. The impact of mining activities on the hypersaline Mar Menor. Desalin. Water Treat. 13, 282-289. http://dx.doi.org/10.5004/dwt.2010.1036.

De León, A.R., Guerrero, J., Farazo, F., 1982. Evolution of the Pollution of the Coastal Lagoon of Mar Menor. VIes Journées Étud. Pollutions, Cannes, pp. 355-358 (C.I.E.S.M.).

Díaz del Rio, V., Somoza, L., 1993. Mapa fisiográfico del Mar Menor. Publicaciones Especiales 14. Instituto Español de Oceanografía (22 pp.).

Font, J., 1987. The path of the Levantine intermediate water to the Alboran Sea. Deep Sea Res., Part I 34 (10), 1745-1755, http://dx.doi.org/10.1016/0198-0149(87)90022-7.

Fujita, M., Ide, Y., Sato, D., Kench, P.S., Kuwahara, Y., Yokoki, H., Kayanne, H., 2014. Heavy metal contamination of coastal lagoon sediments: Fongafale Islet, Funafuti Atoll Tuvalu. Chemosphere 95, 628-634. http://dx.doi.org/10.1016/j.chemosphere.2013. 10.023 .

García, C., 2004. Impacto y riesgo medioambiental en los residuos minerometalúrgicos de la Sierra de Cartagena-La Unión Ph.D. Thesis Universidad Politécnica de Cartagena Cartagena, Spain.

Gibbs, R.J., 1977. Transport phases of transition metals in the Amazon and Yukon Rivers. Geol. Soc. Am. Bull. 88, 829-843. http://dx.doi.org/10.1130/0016-7606(1977)88<829: TPOTMI $>2.0 . \mathrm{CO} ; 2$.

González-Fernández, O., Jurado-Roldán, A.M., Queralt, I., 2010. Geochemical and mineralogical features of overbank and stream sediments of the Beal wadi (Cartagena-La Union mining district, SE Spain): relation to former lead-zinc mining activities and its environmental risk. Water Air Soil Pollut. 215 (1-4), 55-65. http://dx.doi.org/10. 1007/s11270-010-0458-1.

Hjulström, F., 1935. Studies on the morphological activity of rivers as illustrated by the River Fyris. Bulletin of the Geological Institute of Uppsala 25 pp. 221-527.

Hodgkin, E.P., 1994. Estuaries and coastal lagoons. In: Hammond, L.S., Synnot, R.N. (Eds.), Marine Biology. Longman Cheshire, Melbourne, Australia, pp. 315-322.

ICDD, 2013. International Centre for Diffraction Data - PDF4 + Relational Powder Diffraction File, Newton Square, PA, USA

Jiménez de Gregorio, F., 1957. El municipio de San Javier en la historia del Mar Menor y su ribera. Ayuntamiento de San Javier, Murcia (185 pp.).

Kouassi, N.L.B., Yao, K.M., Trokourey, A., Soro, M.B., 2015. Distribution, sources, and possible adverse biological effects of trace metals in surface sediments of a tropical estuary. Environ. Forensics 16, 96-108. http://dx.doi.org/10.1080/15275922.2014.991433.

Loring, D.H., 1991. Normalization of heavy-metal data from estuarine and coastal sediments. ICES J. Mar. Sci. 48, 101-115. http://dx.doi.org/10.1093/icesjms/48.1.101.

Lozano, F., 1954. Una campaña de prospección pesquera en el Mar Menor (Murcia). Bol. Inst. Esp. Oceanogr. 66

Lu, H.Y., An, Z.S., 1997. The influence of pre-treatment to grain size analysis results of loess. Chin. Sci. Bull. 42, 2535-2538.

Manteca Martinez, J.I., Ovejero Zappino, G., 1992. Los yacimientos Zn, Pb, Ag-Fe del distrito minero de la La Unión-Cartagena, Bética Oriental. Recursos Minerales de España, pp. 1085-1102.

Margui, E., Queralt, I., Van Grieken, R., 2009. Sample preparation for X-ray fluorescence analysis. In: Meyers, R.A. (Ed.), Encyclopedia of Analytical Chemistry: Applications, Theory, and Instrumentation. Wiley Interscience, New York, USA. 
Marín-Guirao, L., Cesar, A., Marín, A., Vita, R., 2005. Assessment of sediment metal contamination in the Mar Menor costal lagoon (SE Spain): metal distribution, toxicity, bioaccumulation and benthic community structure. Cienc. Mar. 31, 413-428.

Martinez-Alvarez, V., Gallego-Elvira, B., Maestre-Valero, J.F., Tanguy, M., 2011. Simultaneous solution for water, heat and salt balances in a Mediterranean coastal lagoon (Mar Menor, Spain). Estuar. Coast. Shelf Sci. 91 (2), 250-261. http://dx.doi.org/10. 1016/j.ecss.2010.10.030.

Mas Hernández, J., 1996. El Mar Menor. Relaciones, diferencias y afinidades entre la laguna costera y el mar Mediterráneo adyacente. Microfichas 7. Instituto Español de Oceanografía (16 pp.).

Navarro, F. de P., 1927. Observaciones sobre el Mar Menor (Murcia). Notas y Resúmenes. Inst. Esp. Oceanog. Ser. II 16 (63 pp.)

Nor, Y.M., 1987. Ecotoxicity of copper to aquatic biota: a review. Environ. Res. 43, 274-282. http://dx.doi.org/10.1016/S0013-9351(87)80078-6.

Oen, I.S., Fernández, J.C., Manteca, J.I., 1975. The lead-zinc and associated ores of La Union, Sierra de Cartagena, Spain. Econ. Geol. 70, 1259-1278.

Pedreros, R., Howa, H.L., Michel, D., 1996. Application of grain size trend analysis for the determination of sediment transport pathways in intertidal areas. Mar. Geol. 135 35-49. http://dx.doi.org/10.1016/S0025-3227(96)00042-4.

Pérez-Ruzafa, A., Marcos, C., Pérez-Ruzafa, 1.M., Ros, J.D., 1987. Evolución de las características ambientales y de los poblamientos del Mar Menor (Murcia, SE de España). An. Biol. 12, 53-65 (Biología Ambiental, 3).

Perez-Ruzafa, A., Fernandez, A.I., Marcos, C., Gilabert, J., Quispe, J.I., Garcia-Charton, J.A 2005. Spatial and temporal variations of hydrological conditions, nutrients and chlorophyll a in a Mediterranean coastal lagoon (Mar Menor, Spain). Hydrobiologia 550, 11-27. http://dx.doi.org/10.1007/s10750-005-4356-2.

Pérez-Ruzafa, A., García-Charton, J.A., Barcala, E., Marcos, C., 2006. Changes in benthic fish assemblages as a consequence of coastal works in a coastal lagoon: the Mar Menor (Spain, Western Mediterranean). Mar. Pollut. Bull. 53, 107-120. http://dx.doi.org/ 10.1016/j.marpolbul.2005.07.014

Perry, C., Taylor, K. (Eds.), 2007. Environmental Sedimentology. Blackwell Publ. Oxford, UK.

Peterson, M.S., Comyns, B.H., Hendon, J.R., Bond, P.J., Duff, G.A., 2000. Habitat use by early life-history stages of fishes and crustaceans along a changing estuarine landscape: differences between natural and altered shoreline sites. Wetl. Ecol. Manag. 8, 209-219.

Polo, M. Egüen, M. Nofuentes, M., Losada, M.A., Baraza, F., 2007. Modelo de gestión integral del Mar Menor (II): forzamiento atmosférico y terrestre del sistema. IX Jornadas Españolas de Costas y Puertos, San Sebastián, Spain.
Pusceddu, A., Sarà, G., Armeni, M., Fabiano, M., Mazzola, A., 1999. Seasonal and spatial changes in the sediment organic matter of a semi-enclosed marine system (W-Mediterranean Sea). Hydrobiologia 397, 59-70. http://dx.doi.org/10.1023/A:1003690313842.

Rae, J.E., Allen, J.R.L., 1993. The significance of organic matter degradation in the interpretation of historical pollution trends in depth profiles of estuarine sediment. Estuaries 16, 678-682. http://dx.doi.org/10.2307/1352804.

Reizopouluo, S., Thessalou-Legaki, M., Nicolaidou, A., 1996. Assessment of disturbance in Mediterranean lagoons: an evaluation of methods. Mar. Biol. 125, 189-197. http:// dx.doi.org/10.1007/BF00350773.

Remmler, M., Kopinke, F.D., Stottmeister, U., 1995. Thermoanalytical methods for characterizing hydrocarbon-sludge-soil mixtures. Thermochim. Acta 263, 101-112. http:// dx.doi.org/10.1016/0040-6031(94)02421-J.

Renzi, M., Bigongiari, N., Focardi, S.E., 2015. Baseline levels of trace elements in coastal sediments from the central Mediterranean (Tuscany, Italy). Chem. Ecol. 31, 34-46. http://dx.doi.org/10.1080/02757540.2014.943200.

Sanger, D.M., Holland, A.F., Hernandez, D.L., 2004. Evaluation of the impacts of dock structures and land use on tidal creek ecosystems in South Carolina estuarine environments. Environ. Manag. 33 (3), 385-400. http://dx.doi.org/10.1007/ s00267-003-0019-0.

Seitz, R.D., Lipcius, R.N., Olmstead, N.H., Seebo, M.S., Lambert, D.M., 2006. Influence of shallow-water habitats and shoreline development on abundance, biomass and diversity of benthic prey and predators in Chesapeake Bay. Mar. Ecol. Prog. Ser. 326, 11-27. http://dx.doi.org/10.3354/meps326011.

Silva, E.M., da Navarro, M.F.T., Barros, A.F., Mota, M.F.V., Chastinet, C.B.A., 2000. Metals in the sediments of Juau Lake (Camaçari Bahia, Brazil) following an episode of industrial contamination. Aquat. Ecosyst. Health Manag. 3, 509-514.

Simonneau, J., 1973. Mar Menor: évolution sédimentologique et géochimique récente du remplissage Ph.D. Thesis, Universite' de Toulouse (172 pp.).

SIOM, 2014. Modelo hidrodinámico del Mar Mediterráneo. Servicio de Información Oceanográfica de la Región de Murcia (https://caamext.carm.es/siom/. Servicio de Pesca y Acuicultura de la Consejería de Agricultura y Agua. Comunidad Autónoma de la Región de Murcia).

Vilar, J.B., Egea Bruno, P.M., 1990. La minería murciana contemporanea (1840-1930). Universidad de Murcia, Academia Alfonso X El Sabio, Excmo. Ayuntamiento de Cartagena, CajaMurcia (Eds.), Spain, 389 pp.

Vilar, J.B., Egea Bruno, P.M., Fernández Gutiérrez, J.C., 1991. La minería murciana contemporánea: 1930-1985. Instituto Tecnólogico Geominero de España (256 pp.). 